\title{
Systematic review and meta- analysis of the safety of chloroquine and hydroxychloroquine from randomized controlled trials on malarial and non-malarial conditions
}

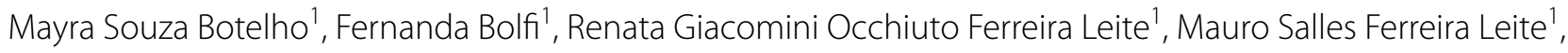
Luisa Rocco Banzato ', Luiza Teixeira Soares' ', Thaina Oliveira Felicio Olivatti ', Amanda Sampaio Mangolim', Flávia Ramos Kazan Oliveira' ${ }^{1}$ Luciana Patrícia Fernandes Abbade², Joelcio Francisco Abbade, Ricardo Augusto Monteiro de Barros Almeida², Julia Simões Corrêa Galendi', Lehana Thabane ${ }^{5,6,7}$ and Vania dos Santos Nunes-Nogueira ${ }^{1 *}$ (1)

\begin{abstract}
Background: Despite the expectations regarding the effectiveness of chloroquine (CQ) and hydroxychloroquine (HCQ) for coronavirus disease (COVID-19) management, concerns about their adverse events have remained.

Objectives: The objective of this systematic review was to evaluate the safety of CQ and HCQ from malarial and nonmalarial randomized clinical trials (RCTs).

Methods: The primary outcomes were the frequencies of serious adverse events (SAEs), retinopathy, and cardiac complications. Search strategies were applied to MEDLINE, EMBASE, LILACS, CENTRAL, Scopus, and Trip databases. We used a random-effects model to pool results across studies and Peto's one-step odds ratio (OR) for event rates below 1\%. Both-armed zero-event studies were excluded from the meta-analyses. We used the Grading of Recommendations Assessment, Development, and Evaluation system to evaluate the certainty of evidence.

Results: One hundred and six RCTs were included. We found no significant difference between CQ/HCQ and control (placebo or non-CQ/HCQ) in the frequency of SAEs (OR: 0.98, 95\% confidence interval [Cl]: 0.76-1.26, 33 trials, 15,942 participants, moderate certainty of evidence). However, there was a moderate certainty of evidence that CQ/HCQ increases the incidence of cardiac complications (RR: 1.62, 95\% Cl: 1.10-2.38, 16 trials, 9908 participants). No clear relationship was observed between CQ/HCQ and retinopathy (OR: 1.63, 95\% Cl: $-0.4-6.57,5$ trials, 344 participants, very low certainty of evidence).
\end{abstract}

*Correspondence: vania.nunes-nogueira@unesp.br

1 Department of Internal Medicine, São Paulo State University/UNESP, Medical School, Sao Paulo, Brazil

Full list of author information is available at the end of the article

(c) The Author(s) 2021. Open Access This article is licensed under a Creative Commons Attribution 4.0 International License, which permits use, sharing, adaptation, distribution and reproduction in any medium or format, as long as you give appropriate credit to the original author(s) and the source, provide a link to the Creative Commons licence, and indicate if changes were made. The images or other third party material in this article are included in the article's Creative Commons licence, unless indicated otherwise in a credit line to the material. If material is not included in the article's Creative Commons licence and your intended use is not permitted by statutory regulation or exceeds the permitted use, you will need to obtain permission directly from the copyright holder. To view a copy of this licence, visit http://creativecommons.org/licenses/by/4.0/. The Creative Commons Public Domain Dedication waiver (http://creativeco mmons.org/publicdomain/zero/1.0/) applies to the data made available in this article, unless otherwise stated in a credit line to the data. 
Conclusions: CQ and HCQ probably do not increase SAEs, with low frequency of these adverse events on malarial and non-malarial conditions. However, they may increase cardiac complications especially in patients with COVID-19. No clear effect of their use on the incidence of retinopathy was observed.

Systematic review registration: PROSPERO CRD42020177818

Keywords: Chloroquine, Hydroxychloroquine, COVID-19, Adverse effects, Safety, Systematic review

\section{Background}

Chloroquine (CQ) and hydroxychloroquine (HCQ) were originally developed for the treatment of malaria; however, several additional drug properties have been discovered, allowing for their use in the treatment of different non-malarial conditions, including rheumatological, dermatological, and immunological diseases [1]. There is also a growing body of evidence to support their therapeutic potential in cancer, chronic kidney disease, and metabolic disorders $[1,2]$.

The in vitro antiviral activity of CQ has been studied for many decades and the growth of different viruses can be inhibited in vitro by both CQ and HCQ [3]. Therefore, the effectiveness of these drugs has been studied in relation to a variety of acute infectious diseases, including Zika, influenza A H5N1, Ebola, dengue, and chikungunya, as well as chronic viral infections, including hepatitis $\mathrm{C}$ and human immunodeficiency virus [3-5].

The most common adverse events (AEs) of these medications are related to gastrointestinal intolerance, such as vomiting, nausea, diarrhea, and abdominal discomfort [6]. Cutaneous manifestations, such as itching, skin rash, photosensitivity, and hyperpigmentation [7] can also occur. Less frequent adverse effects, such as myopathy, neuromyopathy, and cardiotoxicity can be more severe and irreversible [1].

Cardiac conduction disorders (bundle branch block and atrioventricular block), heart failure, ventricular hypertrophy, hypokinesia, valve dysfunction, pulmonary hypertension, and QT prolongation are side effects associated with CQ and HCQ [8].

A long-term $\mathrm{AE}$ associated with these medications is retinopathy, which can cause irreversible visual damage. The risk of development is $1 \%$ after 5 years of chronic use, which increases to 2 and $20 \%$ when used for more than 10 and 20 years, respectively [9].

Faced with the health crisis triggered by the coronavirus disease (COVID-19) pandemic and the absence of a specific drug therapy so far, CQ and HCQ have been evaluated for their possible effectiveness in the treatment of this disease [10]. Nevertheless, despite the expectations regarding their effectiveness, the concern about their adverse side effects has remained. Some researchers consider that a wide use of the drugs will expose some patients to rare but potentially fatal side effects [11], and those who believe in their potential efficacy justify that these medications have a well-established safety profile.

Therefore, as these drugs have been used for many decades for malarial and non-malarial conditions, we conducted a systematic review of randomized clinical trials (RCTs) to evaluate the safety of CQ/HCQ in different conditions and populations.

\section{Methods}

This systematic review was conducted according to Cochrane Collaboration [12] and reported according to Preferred Reporting Items for Systematic Reviews and Meta-Analyses (PRISMA) Statement [13]. Its protocol was registered in the International Prospective Register of Systematic Reviews (CRD42020177818).

\section{Eligibility criteria}

We selected studies that meet the "PICOS" structure described below.

\section{Participants (P)}

An individual, regardless of gender and age, diagnosed with a malarial or non-malarial condition, whose treatment was with either CQ or HCQ.

\section{Types of interventions (I) CQ or HCQ.}

\section{Comparison (C)}

The comparison group was placebo or no $\mathrm{CQ} / \mathrm{HCQ}$. Intervention and comparison groups must have received the same standard treatments for the patient's basal disease.

\section{Outcomes (0)}

The primary outcomes were the number of patients with serious adverse events (SAEs), the number of patients with retinopathy, and the number of patients with cardiac complications.

We considered any $\mathrm{AE}$ or suspected adverse reaction that resulted in any of the following outcomes as SAE: death, a life-threatening $\mathrm{AE}$, hospitalization or prolongation of existing hospitalization, a persistent or significant 
incapacity, substantial disruption of the ability to conduct normal life functions, or a congenital anomaly/birth defect [14].

We considered retinopathy diagnosed after the use of CQ/HCQ in patients who previously had normal baseline ophthalmologic examination results as CQ/ HCQ-induced retinopathy. We considered conduction disorders and other non-specific adverse cardiac events (ventricular hypertrophy, hypokinesia, heart failure, pulmonary arterial hypertension, and valvular dysfunction) as cardiac $\mathrm{AE}$ with probable association with $\mathrm{CQ}$ or HCQ [8].

The secondary outcomes were the total number of participants with any CQ- or HCQ-related AE, number of withdrawals due to $\mathrm{CQ}$ - or $\mathrm{HCQ}$-related $\mathrm{AE}$, number of patients with gastrointestinal AEs (nausea, vomiting, stomach ache, diarrhea, loss of appetite, and weight loss) [1], number of patients with cutaneous manifestations (skin rash, itching, hair loss, erythroderma, exfoliative dermatitis, urticaria, eczematous eruptions, photosensitivity, and erythema annulare centrifugum) [1], number of patients with myopathy, number of patients with visual symptoms, and number of patients with auditory symptoms.

\section{Study design (S)}

We included only RCTs.

\section{Time of outcome evaluation}

The outcomes were evaluated at 4 weeks and after 4 weeks. Trials with outcomes within these time-points were combined with the closest time-point.

\section{Exclusion criteria}

We excluded non-RCTs as well as studies where intervention and comparison groups received different standard treatments for the patient's basal disease.

\section{Identification of studies \\ Electronic databases}

General search strategies were applied to the main electronic health databases: Embase (Elsevier, 198011th April 2020), Medline (PubMed, 1966-11th April 2020), LILACS (Virtual Health Library, 1982-11th April 2020), CENTRAL (Controlled Clinical Trials of Cochrane Collaboration, 1982-11th April 2020), Trip database, SCOPUS, and Web of Science (20th April 2020). A second search on all databases was conducted on 11th April 2021. The search strategies contained index terms and synonyms of chloroquine and hydroxychloroquine. On PubMed, we used the filter for RCT, as supported by Cochrane, and the embedded filter was used for the same purpose on Embase.
The search strategy for each database is included in the Supplementary file. References of relevant primary and secondary studies were searched to identify additional eligible studies. As a huge number of studies met our eligibility criteria, the search for unpublished sources (clinical study report, trial registers, and regulatory agency websites) will be performed in a near future.

EndNote X9 citation management software was used to download references and remove duplicate entries. The initial screening of abstracts and titles was performed using the free web application Rayyan QCRI [15].

\section{Study selection}

Two reviewers (MSB and VSNN) independently selected potentially eligible studies for inclusion in the review based on the titles and abstracts. The studies selected for full-text review were subsequently assessed for adequacy to the proposed 'PICO' structure. In case of disagreement, there was a consensus meeting between the reviewers for a final decision.

\section{Data extraction and management}

The two reviewers (MSB and VSNN) independently used a standard form to extract the following data from the selected studies: year of publication, country, pragmatic or non-pragmatic RCT, basal disorder, population group (children, adults, and pregnant women), sample size, follow-up time, type of intervention and comparison, daily dosage of the intervention, number of patients randomized to intervention and comparison group, number of patients in each group with the primary and secondary outcomes, and mean age of participants.

For a specific outcome, we only extracted data as "zero" if it was clearly listed as such in the study report; otherwise, we interpreted that the authors did not evaluate this outcome.

To ensure consistency between reviewers, we performed a calibration exercise before beginning the review. In the case of duplicate publications or multiple reports from the primary study, data extraction was optimized using the best information available for all items in the same study.

\section{Assessment of risk of bias in included studies}

For the primary outcomes from each selected trial, the risk of bias was assessed according to the revised Cochrane risk-of-bias tool for RCTs (RoB 2 tool) [16], which considered five domains for each outcome evaluated. The domains were (1) bias arising from the randomization process, (2) bias due to deviations from intended interventions, (3) bias due to missing outcome 
data, (4) bias in the measurement of the outcome, (5) bias in the selection of the reported result. For cluster randomized trials we used a specific Rob2 tool for cluster RCTs. Each of the items was evaluated in pairs and independently by 14 reviewers as having "low risk of bias," "some concerns," or "high risk of bias" on 10th August 2020 and 8th June 2021. We classified SAEs as the outcome available for all or nearly all participants, with less than $5 \%$ loss to follow-up. For studies in which such losses were higher than $5 \%$, we considered a low risk of bias in this domain if the rates were balanced between groups, the causes were justified, and not related with any SAE. For outcomes where assessors were aware of the intervention received by study participants, we considered that the assessment of the retinopathy and cardiac complications could have been influenced by the knowledge of the intervention received, but not for SAE. For cardiac complications in open-label studies where there was no information that all participants were subjected to the same method and frequency of investigation, we considered that the measurement or ascertainment of the outcomes might be different between the groups.

\section{Unit of analysis}

The unit of analysis was the data published in the studies included. We used the data available in published articles, and we preferentially used data from intentionto-treat analysis. For the studies that did not provide an intention to treat analysis, we considered the number of patients randomized in each group, and for patients who missed the follow-up, we input as absent the AE evaluated [17]. For the multi-arm trials, we only selected the groups in which the intervention (HCQ/CQ) and the control (non-intervention or placebo) received the same standard treatments for the patient's basal disease. For the multi-arm trials with different regimen doses, we combined the groups in which CQ/HCQ were administered.

For the cluster randomized trials, we used a formula suggested by the Cochrane handbook to find the trial's effective sample size, which is its original sample size divided by the "design effect." The design effect can be calculated by $1+(M-1) \times$ ICC, where $M$ is the average cluster size and ICC is the intracluster correlation coefficient [12].

\section{Data analyses}

Similar outcomes were plotted in the meta-analysis using the Stata Statistical Software 17 (Stata Statistical Software: Release 17. College Station, TX: StataCorp LLC). The relative risk (RR) was calculated with a $95 \%$ confidence interval (CI) as an effect size of CQ/HCQ, and a random-effect model was used for the meta-analysis. However, as this systematic review involved safety measures, and to avoid underestimating the harm, we used Peto's one-step odds ratio (OR) method for event rates below 1\% [12, 18]. In this situation, both-armed zero-event (BAOE) studies were excluded from the meta-analysis.

\section{Sensitivity analysis}

For SAE, we performed sensitivity analyses according to the risk of bias ("high risk" versus "some concerns" versus "low risk"), according to the comparison group (placebo versus no $C Q / H C Q)$, and sample size ( $\geq 100$ participants versus $<100$ participants). For SAE and cardiac complications, we added per-protocol analyses.

\section{Subgroup analysis}

For SAE, we performed subgroup analyses according to the type of intervention (CQ or HCQ), patient diagnosis, type of population (children, adults, and pregnant women), daily dosage $(<500 \mathrm{mg}$ versus $\geq 500 \mathrm{mg}$ for $\mathrm{CQ},<400 \mathrm{mg}$ versus $\geq 400 \mathrm{mg}$ for $\mathrm{HCQ}$ ), time of follow up ( $\leq 4$ weeks versus $>4$ weeks). We used the instrument to assess the Credibility of Effect Modification Analyses (ICEMAN tool) to assess the credibility of the subgroups [19].

\section{Heterogeneity assessment}

Inconsistencies between the results of the studies included were ascertained by visual inspection of forest plots (no overlap of CIs around the effect estimates of the individual studies) and by Higgins or $I^{2}$ statistic, in which $I^{2}>50 \%$ indicated a moderate probability of heterogeneity, and by chi-squared tests $\left(\mathrm{Chi}^{2}\right)$, where $p<0.10$ indicated heterogeneity.

\section{Quality of evidence}

The quality of the evidence of the effect size was assessed according to the Grading of Recommendations Assessment, Development, and Evaluation (GRADE) guidelines [20]. GRADE is a structured process for rating the quality of evidence in systematic reviews or in guidelines for health care [21]. Randomized controlled trials begin as high-quality evidence; however, the confidence in the evidence may decrease if the studies have major limitations that may interfere with the estimates of the treatment effect [21]. These limitations include the risk of bias, inconsistency of results, indirectness of evidence, imprecision, and reporting bias [22].

\section{Results}

The search strategies yielded different studies, and after removing duplicates, 8094 studies remained. We selected 207 studies that had a high probability of meeting our 
1st Search

April $20^{\text {th }} \mathbf{2 0 2 0}$
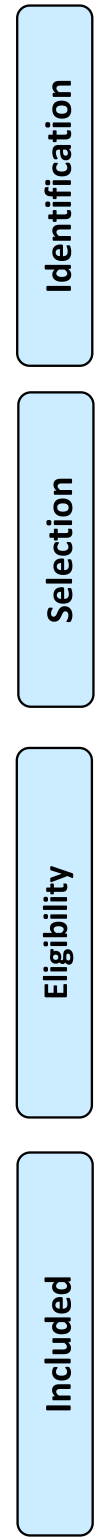

2nd Search

April 11 2021

Articles identified in electronic databases Medline, Embase, Lilacs, CENTRAL

$(n=1844)$ identified by manual search $(n=8)$

Full-text articles excluded, with reasons

$$
(n=101)
$$

\#60 No eligibility criteria

\# 25 Ongoing

\#16 No access to full paper

Fig. 1 Flow diagram of selected studies

inclusion criteria for a complete examination (Fig. 1). After completely examining these references, 106 studies met our eligibility criteria and therefore were included in this review.

A total of 101 studies were excluded for the following reasons: no AE was evaluated $(n=40)$, no control group as placebo or non-comparator for CQ or HCQ $(n=9)$, non-RCT $(n=5)$, no report of the outcomes per group studied $(n=6)$ (Supplementary file), studies are still ongoing $(n=25)$ (Supplementary file), and unevaluated eligibility criteria $(n=16)$ (Supplementary file). 


\section{Study characteristics}

Out of 106 studies included, 20 were on COVID-19 [23-42], 13 studies were on malaria [43-55], 11 on other infectious conditions [56-67], 31 were on rheumatology [68-98], four on dermatologic diseases [99-102], eight on cancer [103-110], seven were on metabolic disease [111-117], and the remaining were on other conditions [118-128]. Seventy-one studies used HCQ $(17,911$ participants) as intervention and 35 used CQ (6997 participants). Most studies used placebo as a comparator, seven studies were on children $[43,44,46,49,52,70,106]$, two on pregnant women $[55,90]$, and the others were on the adult population. Most studies used daily intervention doses $\geq 500 \mathrm{mg}$ for CQ and $\geq 400 \mathrm{mg}$ for HCQ. Rajasinghan et al's trial was the only multi-arm trial whose groups received different doses of the same intervention [39]. We combined the groups in which HCQ were administered. We included one cluster randomized trial, Mitjà et al, in the meta-analyses [37].

In most of the included studies, the participants had chronic conditions, and, consequently, the intervention and follow-up were beyond 4 weeks. Meanwhile, the total sample size was higher in studies on acute conditions, with follow-up less than 4 weeks. Table 1 presents descriptive data of all the studies included.

\section{Risk of bias}

Figure 2 shows the risk of bias corresponding to the included studies for the SAE outcome, and Fig. XIX and Fig. XX in the Supplementary file, respectively, present the risk of bias for retinopathy and cardiac complications. Regarding SAEs, most studies were assessed as low risk of bias, while some were classified as some concerns or high risk due mainly to randomization process or missing outcome data. For retinopathy, most studies did not mention the method used to evaluate this outcome, and because of that, they were classified mostly as some concerns or high risk of bias. For cardiac complications, the open-label RCTs were graduated as some concerns of risk of bias due to no information if participants of both groups were submitted to the same method and frequency of the outcome evaluation.

\section{Meta-analysis}

Regarding primary outcomes, there is no evidence to support the difference between $\mathrm{CQ} / \mathrm{HCQ}$ and the control group (placebo or non-CQ/HCQ) with regard to the frequency of SAE (OR: 0.98, 95\% CI: 0.76-1.26, 33 studies, 15,942 participants, moderate certainty of evidence, Table 2, Fig. 3). Forty BAOE studies with 5440 participants were excluded from this analysis (Fig. 3). Applying the GRADE approach, due to non-inclusion of unpublished data, the quality of evidence was rated down in one level.

Regarding the association between $\mathrm{CQ} / \mathrm{HCQ}$ and the frequency of retinopathy, the evaluation of the risk of bias and imprecision (wide confidence interval, no achievement of optimal information size) did not indicate any clear effect (OR: 1.63, 95\% CI: - 0.4-6.57, 5 studies, 344 participants, very low certainty of evidence, Fig. 4, Table 2). Twenty BAOE studies with 1559 participants were excluded from this analysis (Fig. 4).

The meta-analysis showed that HCQ increases the incidence of cardiac complications (RR: 1.62, 95\% CI: 1.1-2.38, 16 trials, 9908 participants, moderate certainty of evidence, Fig. 5, Table 2), six BAOE studies were excluded from this analysis. Out of the 16 RCTs included in this meta-analysis, 11 were in COVID-19 patients (10,390 participants). Applying Rob2, the open-label RCTs were evaluated considering some concerns about the risk of bias in the measurement of this outcome. It occurred because there is no information if participants of both groups were submitted to the same method and frequency of the evaluation of cardiac complications. Consequently, the quality of evidence was rated down. The complications reported were cardiac arrhythmia and prolongation of QTc interval. Two studies reported these complications as SAE (a prolonged QT interval with ventricular arrhythmias, and a case of torsades de pointes) [26, 85]. The sensitivity analysis per protocol did not change the effect size of HCQ in these outcomes (Supplementary file).

For the secondary outcomes, the administration of CQ/ HCQ increases the incidence of total AE (RR 1.45, 95\% CI: 1.26-1.69, 51 studies, 13,034 participants, Supplementary file), nausea/vomiting (RR 1.93 95\% CI: $1.51-$ 2.49, 26 studies, 7981 participants, Supplementary file), diarrhea (RR 2.04\% CI: 1.41-2.93, 23 studies, 8378 participants, Supplementary file), withdrawal due to AE (RR 1.38, 95\% CI: 1.12-1.71, 41 studies, 7472 participants, Supplementary file), auditory symptoms (RR 1.82, 95\% CI: 1.09 to 3.03 , 9 studies, 5199 participants) and dermatological affections (RR 1.62, 95\% CI: 1.18-2.23, 20 studies, 7026 participants, Supplementary file). There was no clear evidence to support a difference between the CQ/ HCQ and control group with regard to visual symptoms and headache (RR 1.59, 95\% CI: 1.00 to 2.54, 26 studies, 9210 participants; RR 1.47, 95\% CI: 1.02-2.13, 29 studies, 9953 participants, respectively, Supplementary file). Only two studies reported myopathy as AE, and no difference was found between the groups.

For SAE, although more than ten studies were included in the meta-analysis, we could not evaluate publication bias by funnel plot or Egger test because all the studies 


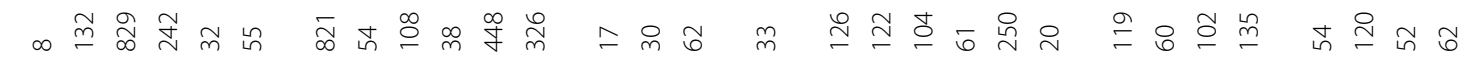

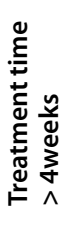

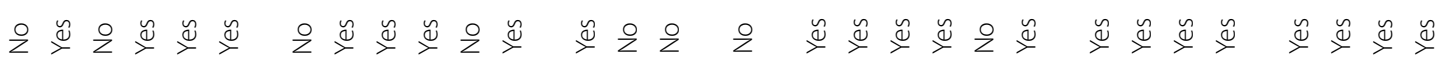

\&

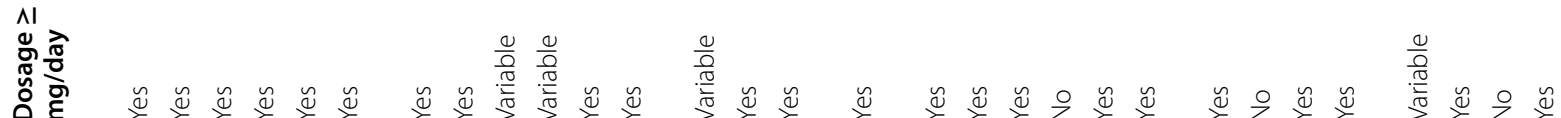

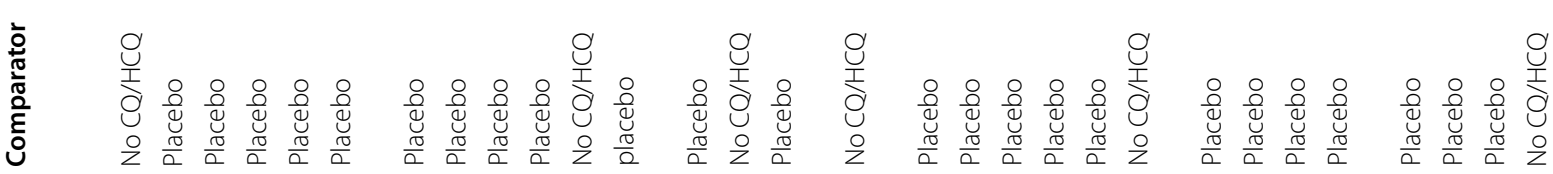

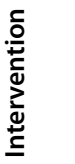

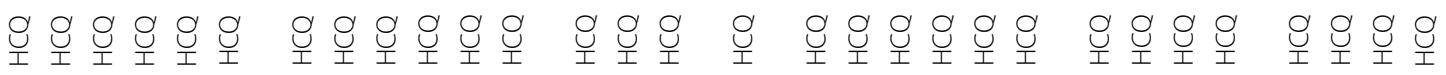

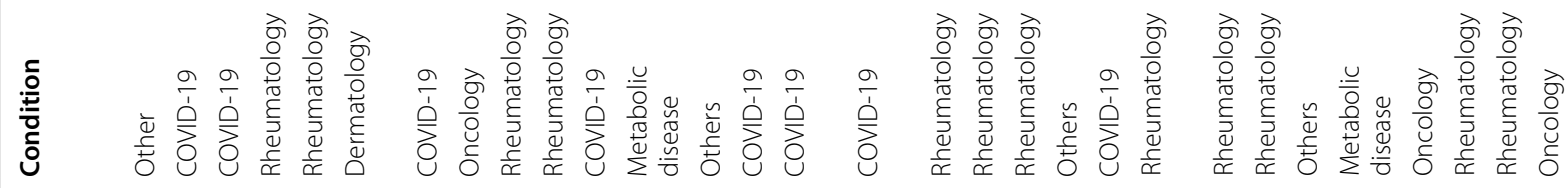
亮 .ำ

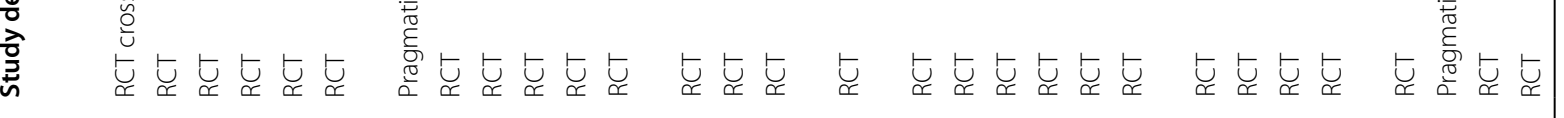

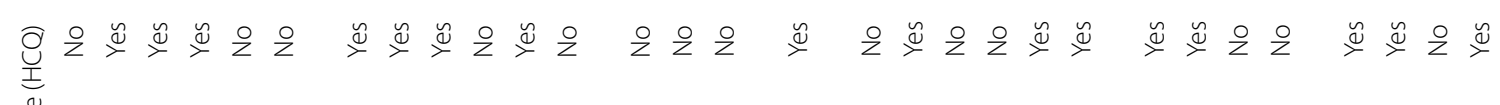

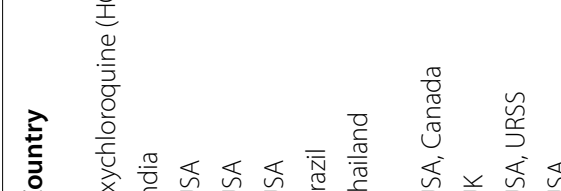




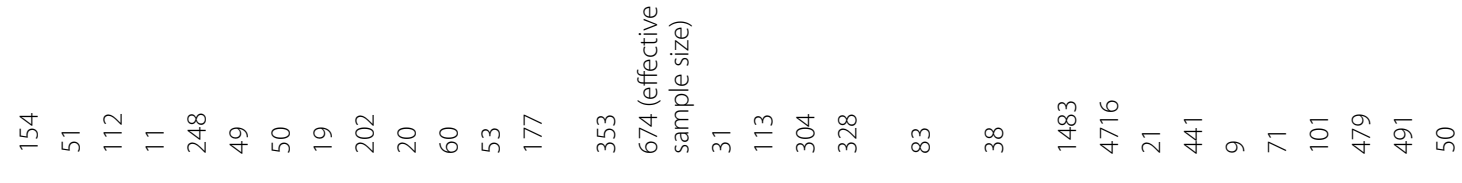

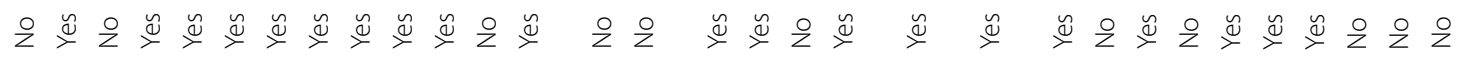

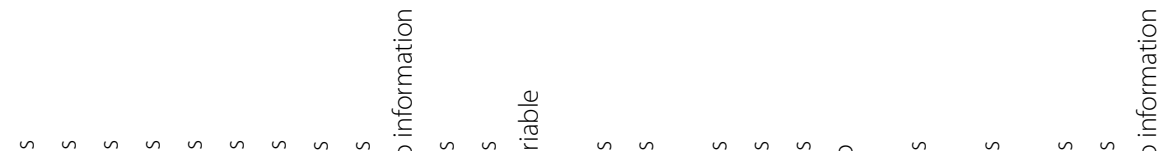

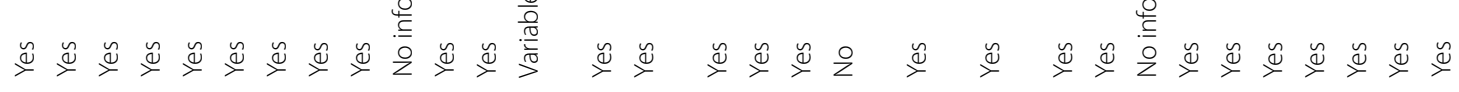

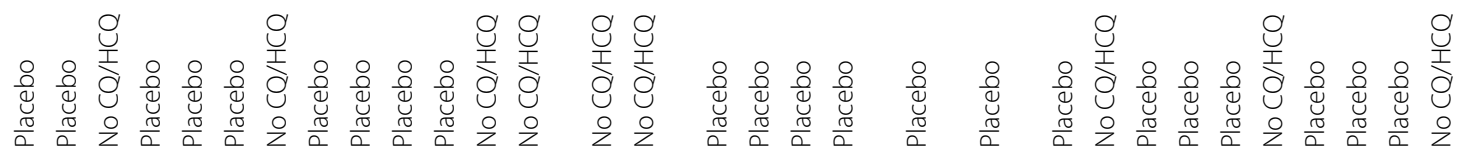

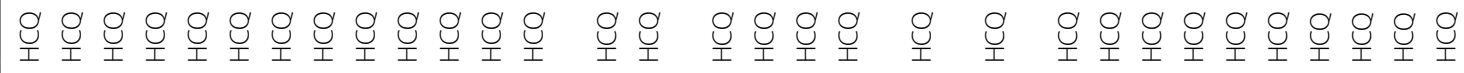

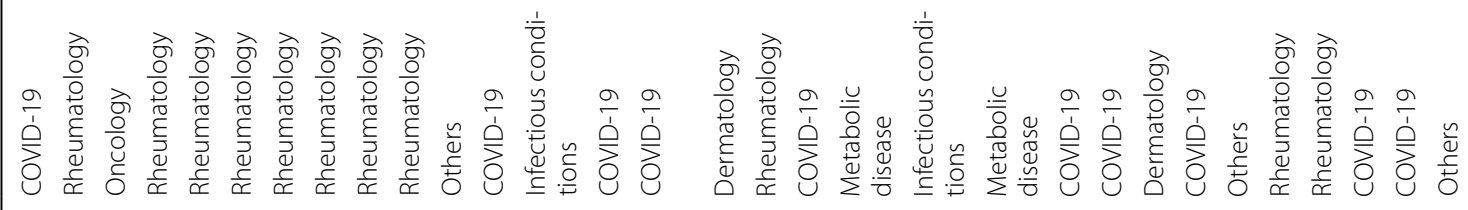

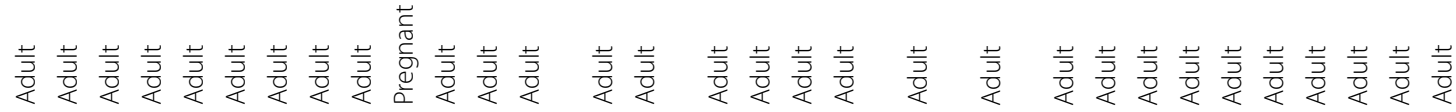

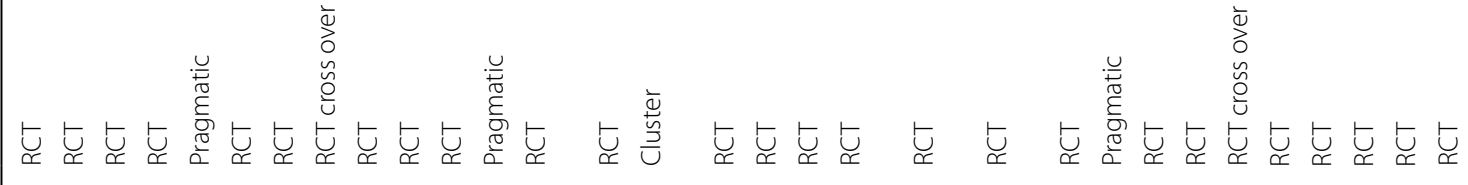

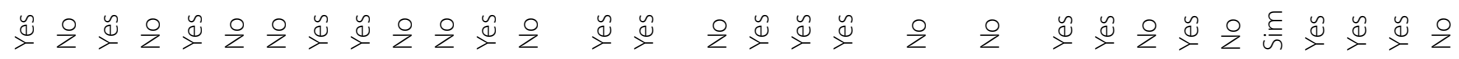

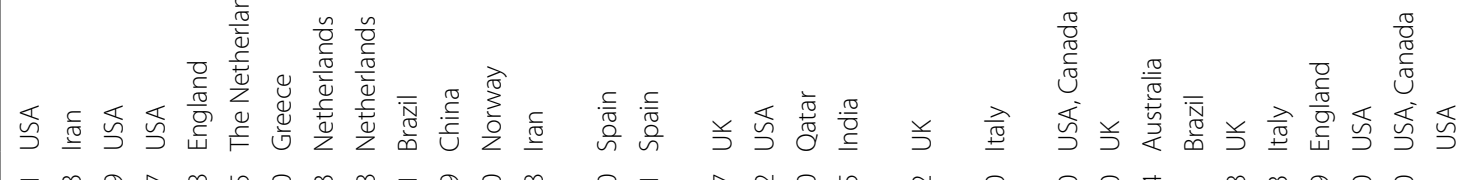

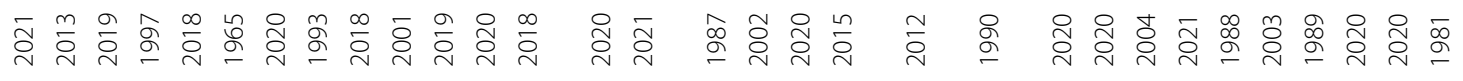

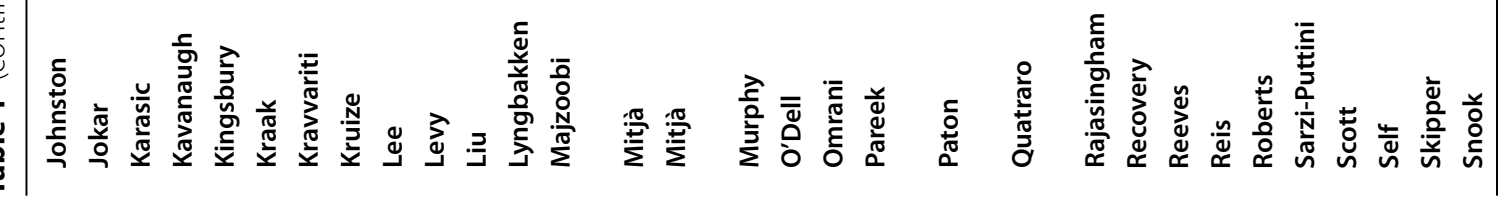




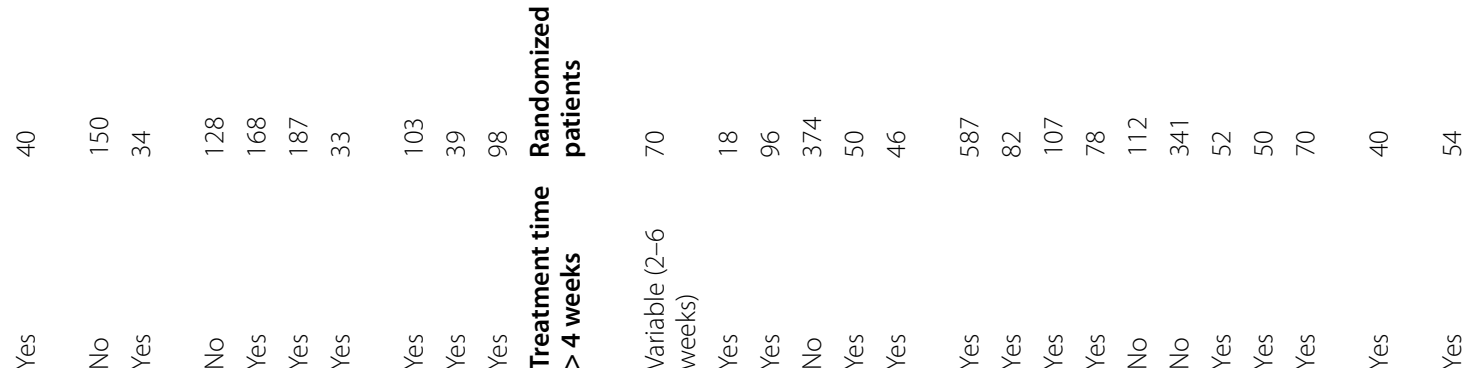
$\stackrel{8}{\circ}$

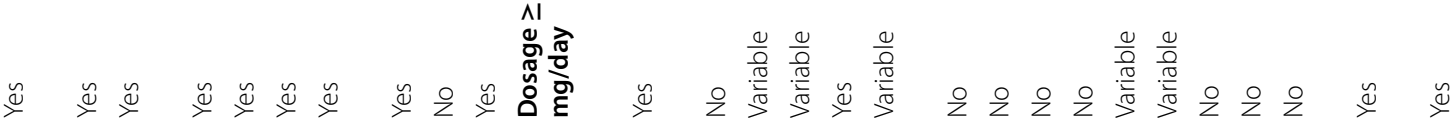

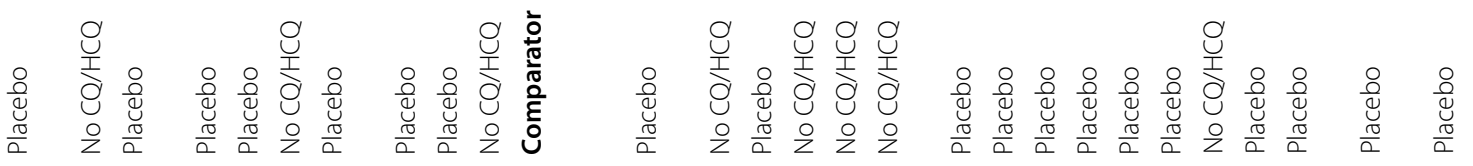

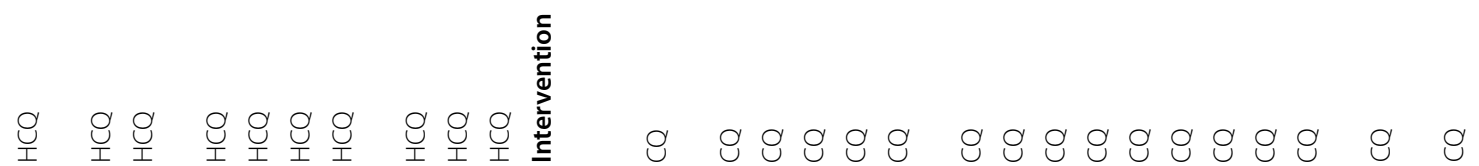

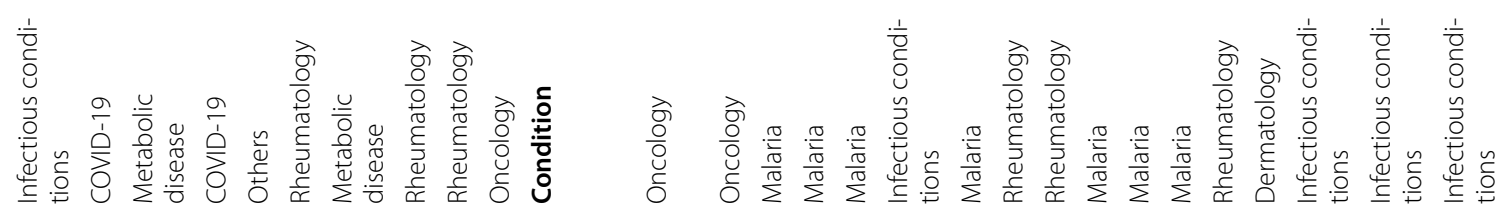

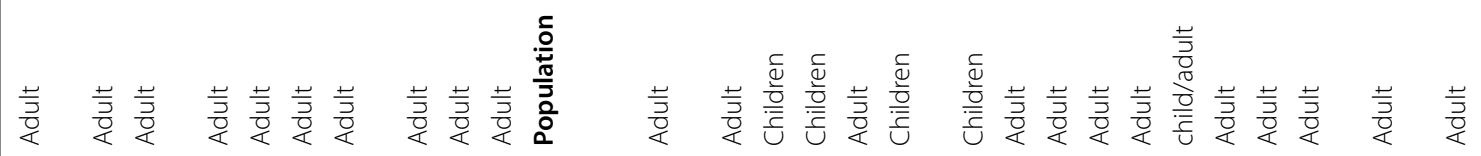

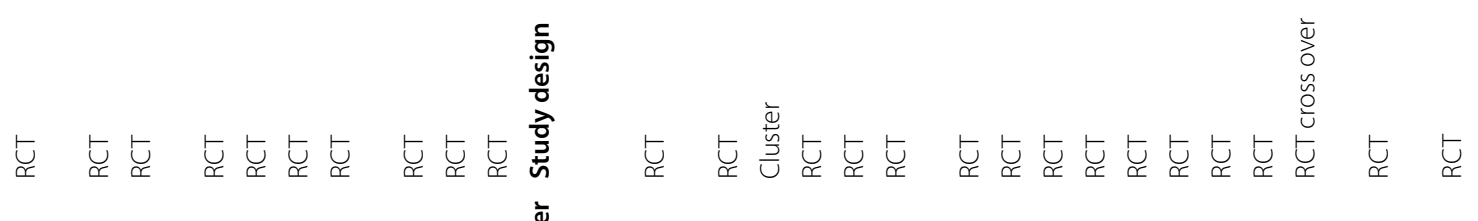

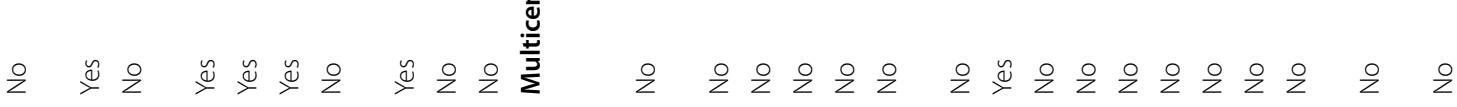

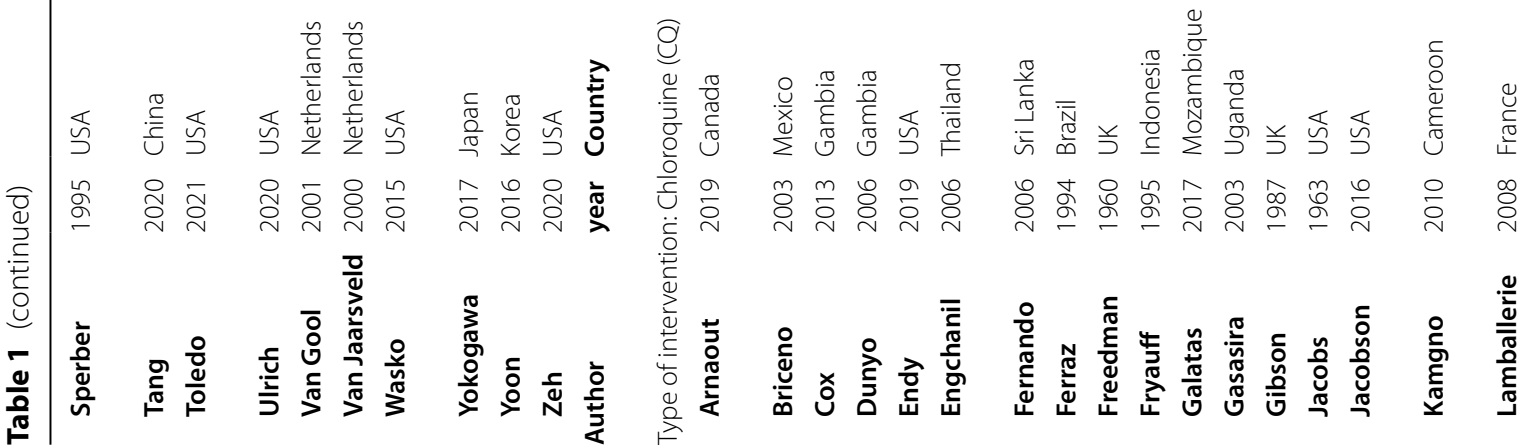


늠

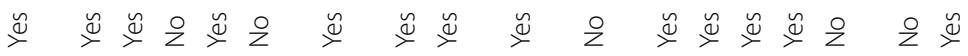

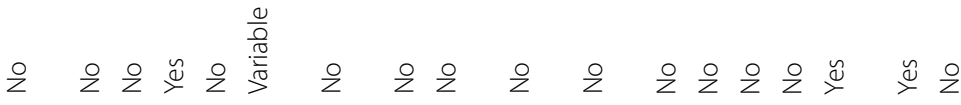

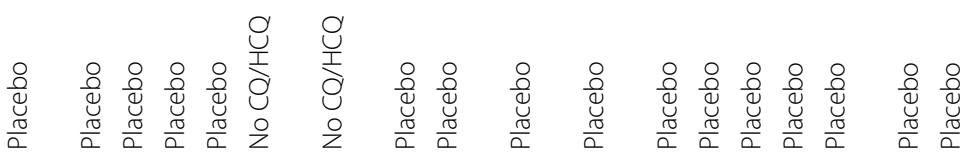

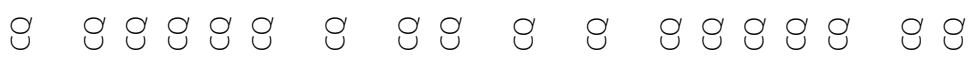

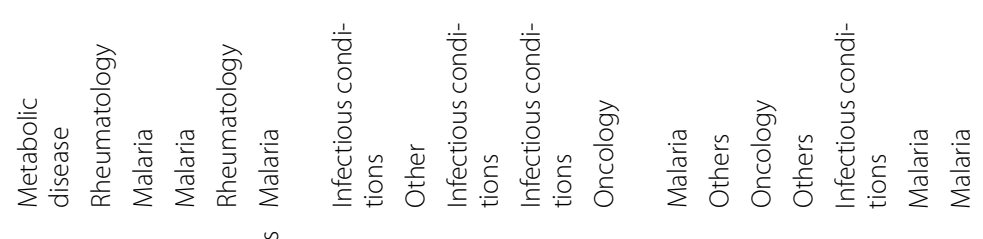

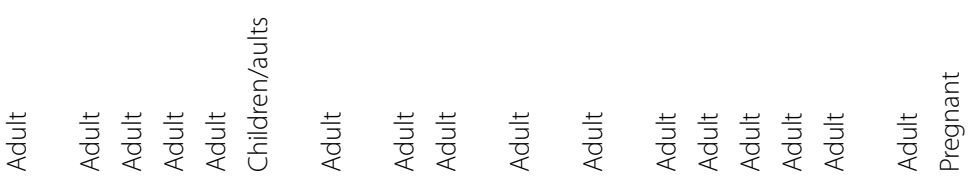

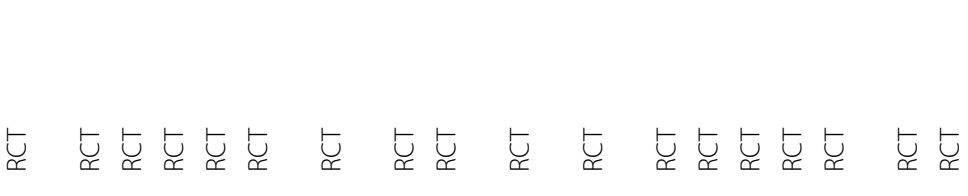

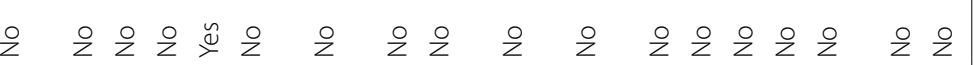

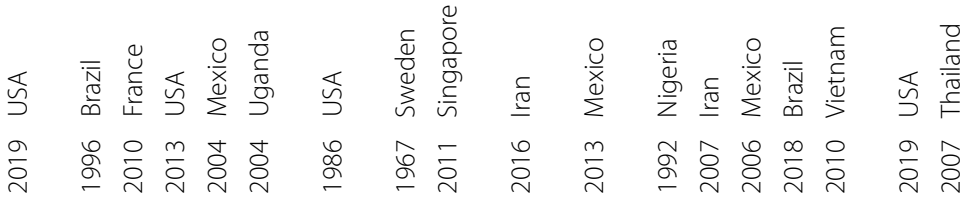

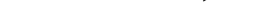

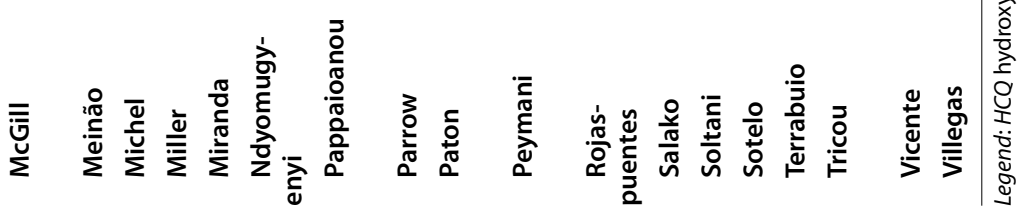



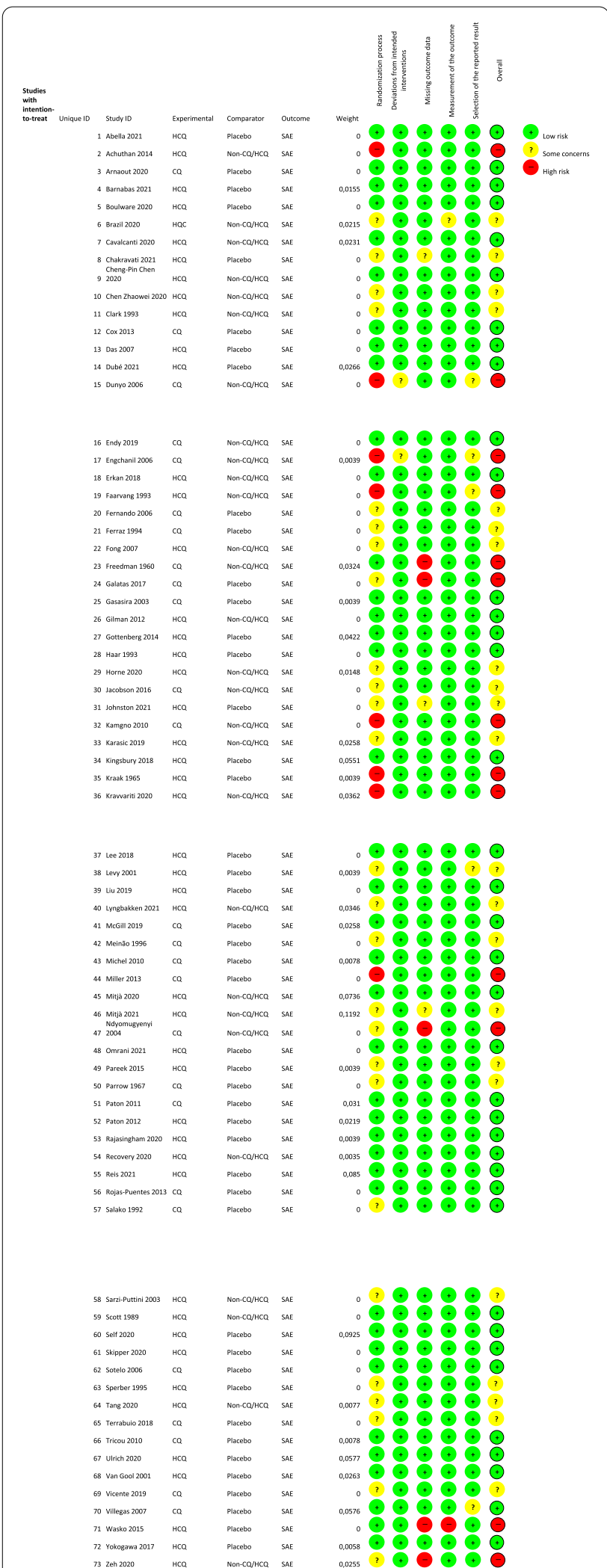

Fig. 2 Risk of bias according to RoB 2 for serious adverse events (SAE) showed no statistically significant difference between groups (CQ/HCQ versus placebo or non-CQ/HCQ). Nevertheless, the quality of evidence in this domain was rated down due to the non-inclusion of unpublished data.

The subgroup analysis according to the type of intervention, patient diagnosis, type of population, daily dosage, and time of follow-up did not indicate that $\mathrm{CQ} / \mathrm{HCQ}$ increased the frequency of SAE (Supplementary file). However, for the subgroup analysis of studies (not for subsets of participants), with 3-4 studies in the smallest subgroup, all the effect modification analyses were classified as having low credibility.

In the sensitivity analyses (according to overall risk of bias, placebo or non-CQ/HCQ, sample size), a "no true" CQ/HCQ effect on SAE was observed (Supplementary file).

\section{Discussion}

Considering the promising action of $\mathrm{CQ}$ and $\mathrm{HCQ}$ in the treatment of COVID-19 at the beginning of the pandemic, many guidelines started to include them in the management of this condition. Consequently, a significant number of patients used these medications, and a great concern emerged regarding their safety. Thus, we conducted a systematic review of RCTs to evaluate the safety of $\mathrm{CQ} / \mathrm{HCQ}$ in different conditions and populations.

We chose, as our primary outcomes, the frequency of rare but potentially fatal AEs: SAEs, retinopathy, and cardiac complications. The study included 106 RCTs, with a total of 24,879 participants. With moderate certainty, we did not find evidence that either CQ or HCQ, compared with placebo or non- $\mathrm{CQ} / \mathrm{HCO}$, increased the frequency of SAEs. However, the HCQ increased the incidence of cardiac complications in the trials whose condition was COVID-19. Due to imprecision and risk of bias, we did not observe any clear effect of $\mathrm{CQ} / \mathrm{HCQ}$ on retinopathy.

Although the literature has reported several CQ/ HCQ-associated AEs, both drugs are generally considered safe [129-132]. One of the explanations that HCQ increased the incidence of cardiac complication is that COVID-19 patients have been considered at an increased risk of cardiac arrhythmias [133]. Moreover, some tachyarrhythmias have been observed in this population, being atrial fibrillation, atrial flutter, ventricular tachycardia, and ventricular fibrillation the most frequent [133]. A systematic review under conditions other than COVID-19 identified 86 case/series studies, providing information on 127 participants with cardiac complications likely to be caused by $\mathrm{CQ} / \mathrm{HCQ}$. Majority of the patients were treated with CQ and most had been treated for a long time (median, 7 years; minimum, 3 days; maximum, 35 years), with high cumulative doses 
Table 2 Summary of findings according to GRADE approach. CQ/HCQ compared to Placebo or no CQ/HCQ for malarial and nonmalarial conditions

\begin{tabular}{|c|c|c|c|c|c|c|}
\hline \multirow[t]{2}{*}{ Outcomes } & \multicolumn{2}{|c|}{$\begin{array}{l}\text { Anticipated absolute effects }{ }^{*}(95 \% \\
\mathrm{Cl})\end{array}$} & \multirow[t]{2}{*}{$\begin{array}{l}\text { Relative effect } \\
(95 \% \mathrm{Cl})\end{array}$} & \multirow[t]{2}{*}{$\begin{array}{l}\text { № of participants } \\
\text { (studies) }\end{array}$} & \multirow{2}{*}{$\begin{array}{l}\text { Certainty of } \\
\text { the evidence } \\
\text { (GRADE) }\end{array}$} & \multirow{2}{*}{ Comments } \\
\hline & $\begin{array}{l}\text { Risk with } \\
\text { placebo/non- } \\
\text { comparator }\end{array}$ & Risk with $\mathrm{HCQ} / \mathrm{CQ}$ & & & & \\
\hline SAE & 14 per 1.000 & $\begin{array}{l}\mathbf{1 5} \text { per } \mathbf{1 . 0 0 0} \\
(12 \text { to } 20)\end{array}$ & OR 0.98 (0.76 to 1.26$)$ & $\begin{array}{l}15942 \\
\text { (33 RCTs) }\end{array}$ & $\begin{array}{l}\oplus \oplus \oplus \bigcirc_{\text {MODERATE }}{ }^{a}\end{array}$ & $\begin{array}{l}\text { CQ/HCQ likely does not } \\
\text { increase SAE. }\end{array}$ \\
\hline Retinopathy & 18 per 1.000 & $\begin{array}{l}\mathbf{2 8} \text { per } \mathbf{1 . 0 0 0} \\
\text { (7 to } 105)\end{array}$ & $\begin{array}{l}\text { OR } 1.63 \\
(0.40 \text { to } 6.57)\end{array}$ & $\begin{array}{l}344 \\
(5 \mathrm{RCTS})\end{array}$ & $\begin{array}{l}\oplus \oplus \bigcirc \bigcirc \\
L^{\circ} W^{b}\end{array}$ & $\begin{array}{l}\text { The evidence is very } \\
\text { uncertain about the } \\
\text { effect of } C Q / H C Q \text { on } \\
\text { retinopathy. }\end{array}$ \\
\hline Cardiac Complications & 20 per 1.000 & $\begin{array}{l}\mathbf{3 7} \text { per } \mathbf{1 . 0 0 0} \\
(25 \text { to } 55)\end{array}$ & $\begin{array}{l}\text { RR } 1.62 \\
\text { (1.10 to } 2.38)\end{array}$ & $\begin{array}{l}9908 \\
(16 R C T s)\end{array}$ & $\begin{array}{l}\oplus \oplus \oplus \bigcirc_{\text {MODERATE }} \\
\end{array}$ & $\begin{array}{l}\text { CQ/HCQ may result in } \\
\text { an increase in cardiac } \\
\text { complications. }\end{array}$ \\
\hline
\end{tabular}

*The risk in the intervention group (and its 95\% confidence interval) is based on the assumed risk in the comparison group and the relative effect of the intervention (and its $95 \% \mathrm{Cl}$ ). $\mathrm{Cl}$ confidence interval, OR odds ratio, $R R$ risk ratio, SAE serious adverse events, CQ chloroquine; HCQ hydroxychloroquine, GRADE Grading of Recommendations Assessment, Development, and Evaluation

GRADE levels of evidence

High certainty: We are very confident that the true effect lies close to that of the estimate of the effect

Moderate certainty: We are moderately confident in the effect estimate: The true effect is likely to be close to the estimate of the effect, but there is a possibility that it is substantially different

Low certainty: Our confidence in the effect estimate is limited: The true effect may be substantially different from the estimate of the effect

Very low certainty: We have very little confidence in the effect estimate: The true effect is likely to be substantially different from the estimate of effect

Explanations

a The quality of evidence was rated down due to non-inclusion of unpublished data

${ }^{\mathrm{b}}$ Considering a prevalence of $7.8 \%$ of retinopathy in non-diabetic population (Klein,1992), and a $1 \%$ of retinopathy risk in the first 5 years of HCQ treatment (Petri 2020 ), the minimum sample size required for detection of this outcome is 4533 (level of significance $=5 \%$; power $=1$ - $\beta=80 \%$ ). Then, the optimal information size criterion was not met, and the confidence interval was wide. Because of this the quality of evidence was rating downed for imprecision

'The open-label RCTs were graduated as some concerns of risk of bias due to no information if participants of both groups were submitted to the same method and frequency of the outcome evaluation

(median, $1235 \mathrm{~g}$ and $803 \mathrm{~g}$ for hydroxychloroquine and chloroquine, respectively). Conduction disorders were the main cardiac complication reported, affecting $85 \%$ of the patients. Moreover, the authors highlighted that case/series studies do not allow for an association of causality, and the risk of cardiac complications attributed to CQ/HCQ could not be quantified [8].

While this review was being performed, two unregistered systematic reviews were published on the same subject. Ren et al. identified RCTs that compared the safety profiles of CQ or HCQ with placebo or other active treatment. Their study included 40 studies, with 2137 participants and 1096 participants in the CQ and HCQ trials, respectively. They used RR as effect size, and they concluded that the overall mild or total AEs were statistically higher with CQ or HCQ than with placebo. From the meta-analysis of SAEs, the RR values for CQ and HCQ were 1.1 (95\% CI: 0.41 to 2.9, six studies) and 1.12 (95\% CI: 0.58 to $2.15,14$ trials), respectively [134]. Eljaaly et al. searched PubMed and EMBASE databases for RCTs of adults comparing AE of HCQ with placebo for any indication. Nine RCTs with a total of 916 patients were included. Cardiac toxicity was not reported, and the meta-analysis found a significantly higher risk of skin pigmentation in HCQ users than in those that received placebo. However, the study did not evaluate the frequency of SAE and retinopathy [135].

Our review included more studies and consequently more participants than the two published reviews. Both reviews included only studies with placebo and the latter included only the studies on HCQ. We did not exclude non-placebo-controlled studies in the evaluation of SAE because we did not believe that the lack of blinding in the outcome assessment, as well as in the intervention received, could cause performance or detection bias. Additionally, we performed a sensitivity analysis separating placebo trials from the trials with non- $\mathrm{CQ} / \mathrm{HCQ}$, and for each subgroup analysis, there was no difference in the frequency of SAE, and the CIs were the same (Supplementary file).

Our systematic review had some limitations. The most significant was that there was no search for unpublished sources of data on AE. This includes clinical study reports, trial registers, and regulatory agency websites [12]. There is strong evidence that much of the 


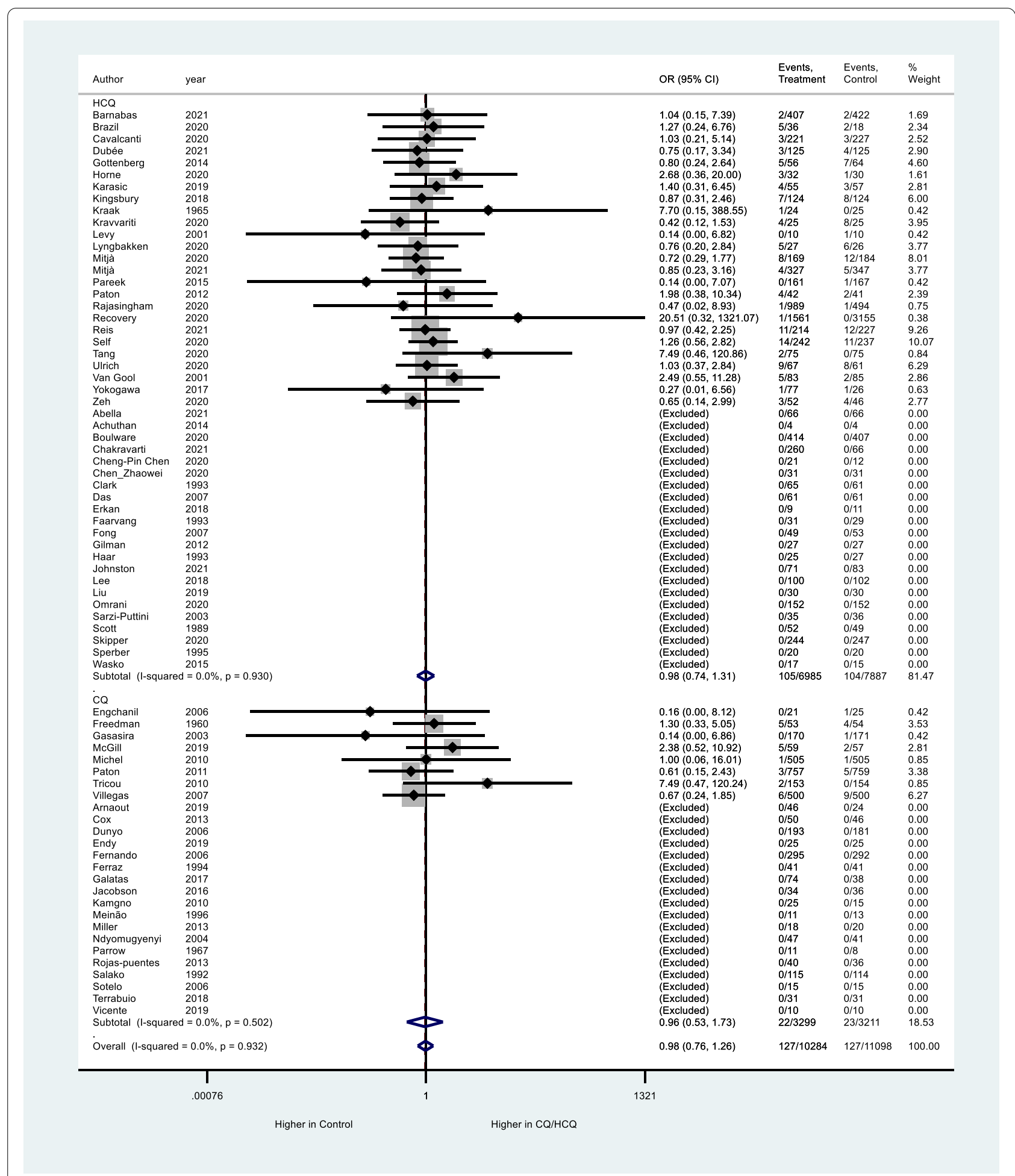

Fig. 3 Meta-analysis for frequency of serious adverse events. Subgroup analysis according to the type of intervention. $C Q$, chloroquine; $H C Q$, hydroxychloroquine. Peto's method was adopted and studies with both-armed zero-event were excluded from the analysis. Significance test(s) of $\mathrm{OR}=1$, overall, $z=0.16, p=0.872$ 


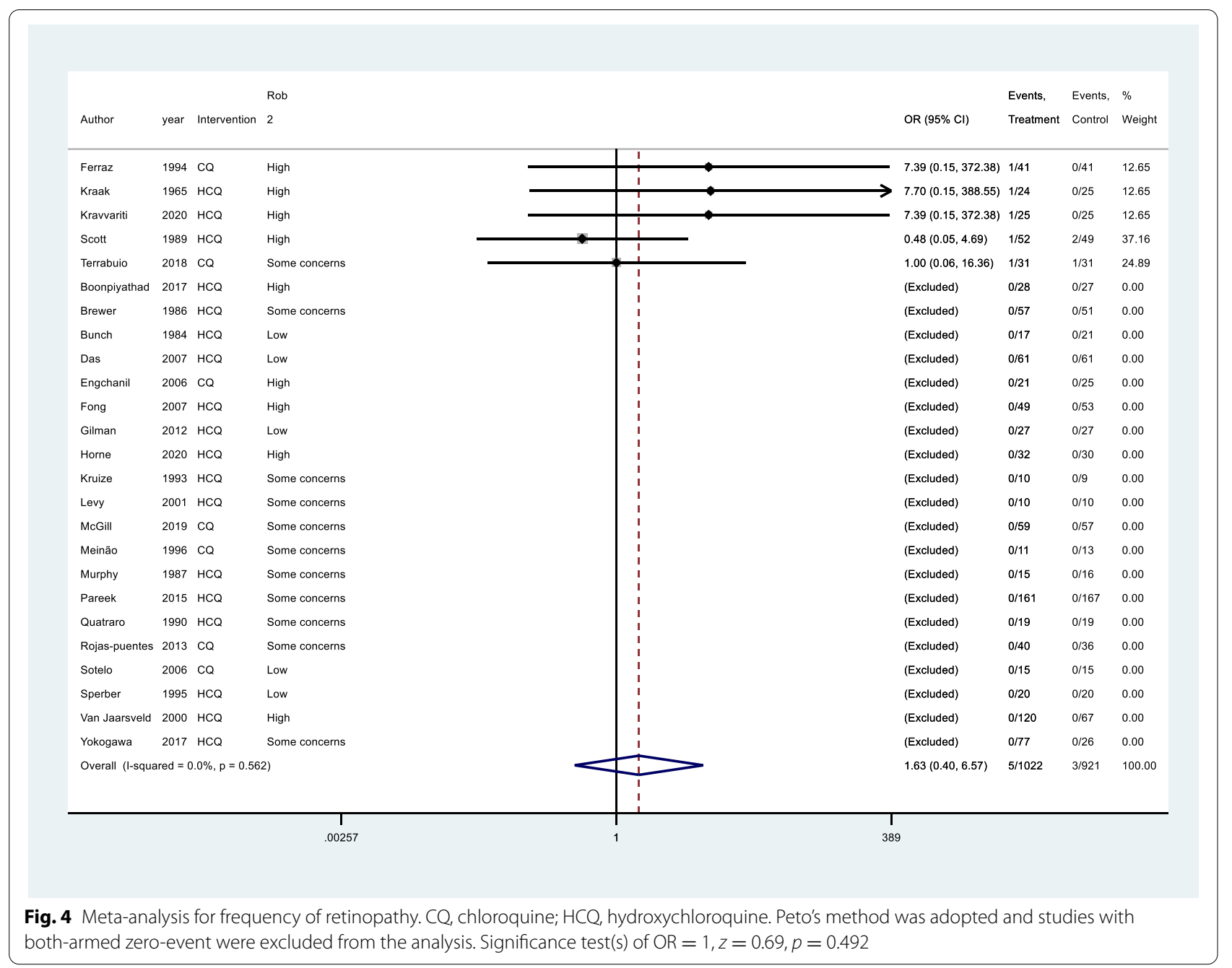

information on $\mathrm{AE}$ are unpublished and that the number and range of $\mathrm{AE}$ are higher in unpublished than in published versions of the same study [136]. Golder and colleagues found that the median percentage of published documents with $\mathrm{AE}$ information was $46 \%$ compared with 95\% in the corresponding unpublished documents [136]. Because of this, we rated down the quality of evidence by one level for publication bias. Additionally, the search for SAE, retinopathy, and cardiac complications related to $\mathrm{CQ} / \mathrm{HCQ}$ from unpublished data will be the next step of this project. The second limitation was the number of BAOE studies that were excluded from the meta-analysis of primary outcomes. As these studies do not provide any indication of direction or magnitude of the relative treatment effect, they are naturally excluded in meta-analysis of OR and RR [12]. However, there is no consensus on whether studies with no observed events in the treatment and control arms should be included or not in a metaanalysis of RCTs. Cheng and collaborators simulated
2500 data sets for rare event outcomes with different scenarios by varying the baseline event rate, treatment effect and number of patients in each trial, and between-study variance [18]. In accordance with another study [137], they concluded that the Peto one-step odds ratio method is the least biased and most powerful method for the meta-analyses of rare events [12]. Additionally, including BAOE studies for AE can underestimate possible harmful side effects, which could expose patients to unnecessary danger. Thus, they recommended that for the analysis of rare AEs, Peto's method should be adopted in conjunction with the exclusion of BAOE studies from analysis. The third limitation was that most of the trials included were not pragmatic studies, and individuals with risk factors for AEs related to CQ/HCQ were excluded. This means that the safety profile of $C Q / H C Q$ presented here was not designed to the real-world, and it could be underestimating harm. 


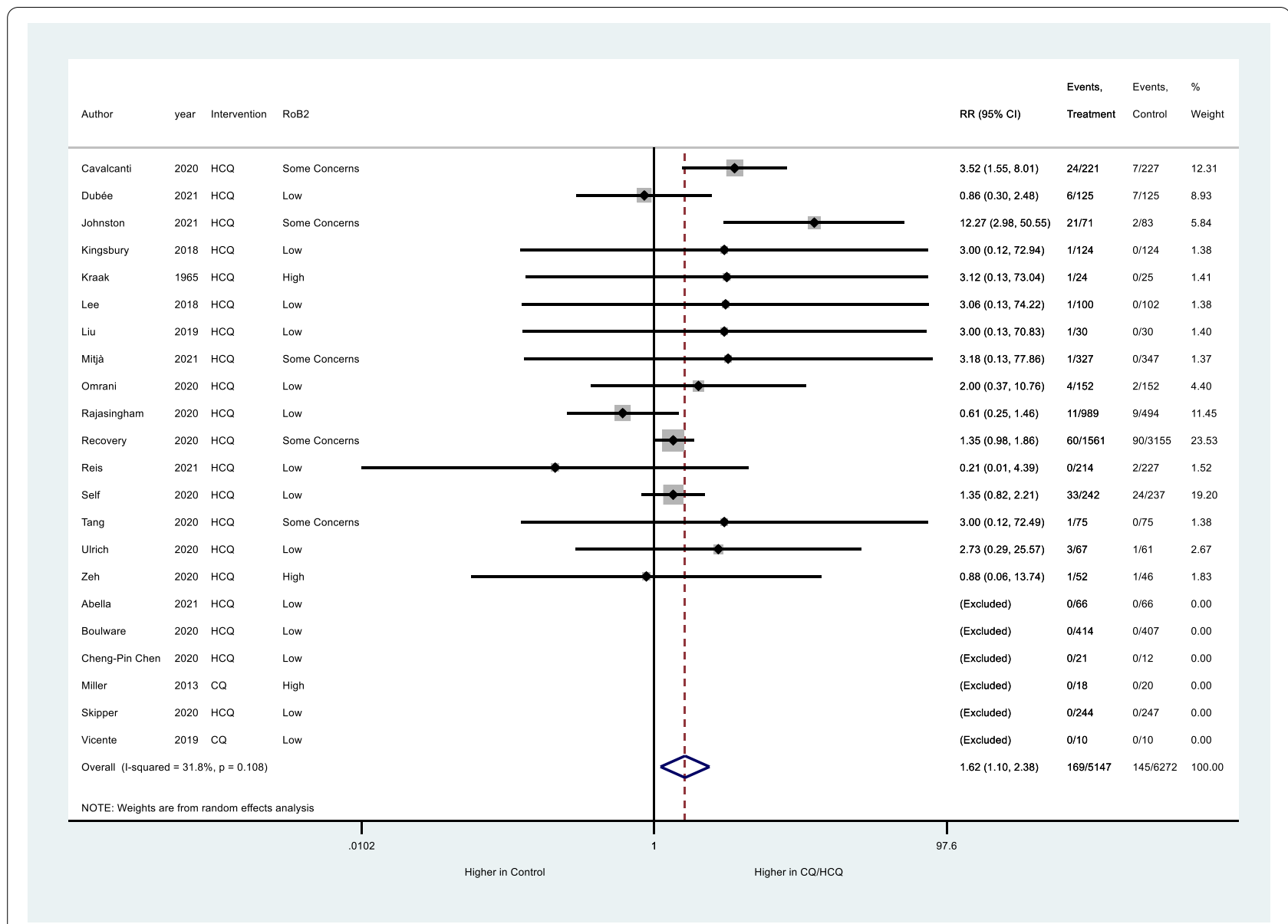

Fig. 5 Meta-analysis for frequency of cardiac complications. Studies with both-armed zero-event were excluded from the analysis. Significance test(s) of $\mathrm{RR}=1, \mathrm{z}=2.60, p=0.009$

\section{Conclusion}

In conclusion, from the findings of this systematic review, CQ and HCQ probably do not increase the frequency of SAE from RCTs on malarial and nonmalarial conditions. However, they may increase cardiac complications in patients with COVID-19. Due to imprecision and bias in the measurement of the outcomes, no clear effect on the incidence of retinopathy was observed.

\section{Abbreviations}

AE: Adverse event; BAOE: Both-armed zero-event; Cl: Confidence interval; CQ: Chloroquine; HCQ: Hydroxychloroquine; OR: Odds ratio; RCT: Randomized controlled trial; RR: Relative risk; SAE: Serious adverse events.

\section{Supplementary Information}

The online version contains supplementary material available at https://doi. org/10.1186/s13643-021-01835-x.

Additional file 1.

\section{Acknowledgements}

The authors thank the São Paulo Research Foundation (grant number: 2018/11836-6) for providing VSNN the meta-analysis short course (Oxford University Department for Continuing Education) and they thank Stata for providing a student short-term license to MSB.

\section{Authors' contributions}

VSNN and LT conceptualized and design the study. VSNN developed the search strategies. VSNN and MSB independently screened eligible studies and extracted data from included studies. VSNN, MSB, FB, RGOFL, MSFL, LRB, LTS, TOFO, ASM, FRKO, LPFA, JFA, RAMBA, and JSCG assessed in pairs and independently the risk of bias. VSNN, LT, and MSB performed the meta-analyses. VSNN supervised all the phases of this review and refereed any disagreement to avoid errors. All authors participated in data synthesis and in the assessment of the quality of evidence. All authors critically revised the manuscript and approved its final version.

\section{Funding}

This study was financed in part by the Coordenação de Aperfeiçoamento de Pessoal de Nível Superior - Brasil (CAPES) - Finance Code 001.

\section{Availability of data and materials}

All data generated or analyzed for this systematic review are included in this published article (and its Supplementary file). 


\section{Declarations}

\section{Consent of publication}

Not applicable.

\section{Ethics approval and consent to participate}

As no primary data collection was carried out, no formal ethical assessment was required by our institution.

\section{Competing interests}

The authors have no conflicts of interest to declare.

\begin{abstract}
Author details
${ }^{1}$ Department of Internal Medicine, São Paulo State University/UNESP, Medical School, Sao Paulo, Brazil. ²Department of Infectious Diseases, Dermatology, Imaging Diagnosis and Radiotherapy, São Paulo State University/UNESP, Medical School, Sao Paulo, Brazil. ${ }^{3}$ Department of Gynecology and Obstetrics, São Paulo State University/UNESP, Medical School, Sao Paulo, Brazil. ${ }^{4}$ Institute of Health Economics and Clinical Epidemiology, Faculty of Medicine and University Hospital of Cologne, University of Cologne, Cologne, Germany. ${ }^{5}$ Department of Health Research Methods, Evidence, and Impact, McMaster University, Hamilton, ON, Canada. ${ }^{6}$ Biostatistics Unit, St Joseph's HealthcareHamilton, Hamilton, ON, Canada. ${ }^{7}$ Faculty of Health Sciences, University of Johannesburg, Johannesburg, South Africa.
\end{abstract}

Received: 9 September 2020 Accepted: 11 October 2021

Published online: 04 November 2021

\section{References}

1. Plantone D, Koudriavtseva T. Current and future use of chloroquine and hydroxychloroquine in infectious, immune, neoplastic, and neurological diseases: a mini-review. Clin Drug Investig. 2018;38(8):653-71.

2. Shukla AM, Wagle Shukla A. Expanding horizons for clinical applications of chloroquine, hydroxychloroquine, and related structural analogues. Drugs Context. 2019;8.

3. Touret F, de Lamballerie X. Of chloroquine and COVID-19. Antivir Res. 2020;177:104762.

4. Helal GK, Gad MA, Abd-Ellah MF, Eid MS. Hydroxychloroquine augments early virological response to pegylated interferon plus ribavirin in genotype-4 chronic hepatitis C patients. J Med Virol. 2016;88(12):2170-8.

5. Chauhan A, Tikoo A. The enigma of the clandestine association between chloroquine and HIV-1 infection. HIV Med. 2015;16(10):585-90

6. Srinivasa A, Tosounidou S, Gordon C. Increased incidence of gastrointestinal side effects in patients taking hydroxychloroquine: a brandrelated issue? J Rheumatol. 2017:44(3):398.

7. Bahloul E, Jallouli M, Garbaa S, Marzouk S, Masmoudi A, Turki H, et al. Hydroxychloroquine-induced hyperpigmentation in systemic diseases: prevalence, clinical features and risk factors: a cross-sectional study of 41 cases. Lupus. 2017;26(12):1304-8.

8. Chatre C, Roubille F, Vernhet H, Jorgensen C, Pers YM. Cardiac complications attributed to chloroquine and hydroxychloroquine: a systematic review of the literature. Drug Saf. 2018:41(10):919-31.

9. Marmor MF, Kellner U, Lai TY, Melles RB, Mieler WF. American Academy of $\mathrm{O}$. Recommendations on screening for chloroquine and hydroxychloroquine retinopathy (2016 Revision). Ophthalmology. 2016:123(6):1386-94.

10. Gautret P, Lagier JC, Parola P, Hoang VT, Meddeb L, Mailhe M, et al. Hydroxychloroquine and azithromycin as a treatment of COVID-19: results of an open-label non-randomized clinical trial. Int J Antimicrob Agents. 2020;105949.

11. Ferner RE, Aronson JK. Chloroquine and hydroxychloroquine in covid19. BMJ. 2020;369:m1432

12. Higgins JPTT, editor. Cochrane handbook for systematic reviews of interventions. 2nd ed. Oxford: The Cochrane Collaboration and John Wiley \& Sons Ltd.; 2019.

13. Liberati A, Altman DG, Tetzlaff J, Mulrow C, Gotzsche PC, loannidis JP, et al. The PRISMA statement for reporting systematic reviews and meta-analyses of studies that evaluate health care interventions: explanation and elaboration. Ann Intern Med. 2009;151(4):W65-94.

14. Administration FUSFD. CFR - Code of Federal Regulations Title 212019 [https://www.accessdata.fda.gov/scripts/cdrh/cfdocs/cfcfr/cfrsearch. $\mathrm{cfm} ? \mathrm{fr}=312.32]$.

15. Ouzzani M, Hammady H, Fedorowicz Z, Elmagarmid A. Rayyan-a web and mobile app for systematic reviews. Syst Rev. 2016;5(1):210.

16. Sterne JACSJ, Page MJ, Elbers RG, Blencowe NS, Boutron I, Cates CJ, et al. RoB 2: a revised tool for assessing risk of bias in randomised trials. BMJ. 2019;366:14898.

17. Egger M, Davey Smith G, Schneider M, Minder C. Bias in meta-analysis detected by a simple, graphical test. BMJ. 1997;315(7109):629-34.

18. Cheng J, Pullenayegum E, Marshall JK, Iorio A, Thabane L. Impact of including or excluding both-armed zero-event studies on using standard meta-analysis methods for rare event outcome: a simulation study. BMJ Open. 2016:6(8):e010983.

19. Schandelmaier S, Briel M, Varadhan R, Schmid CH, Devasenapathy $\mathrm{N}$, Hayward RA, et al. Development of the Instrument to assess the Credibility of Effect Modification Analyses (ICEMAN) in randomized controlled trials and meta-analyses. CMAJ. 2020;192(32):E901-E6.

20. Alonso-Coello P, Oxman AD, Moberg J, Brignardello-Petersen R, Akl EA, Davoli M, et al. GRADE Evidence to Decision (EtD) frameworks: a systematic and transparent approach to making well informed healthcare choices. 2: Clinical practice guidelines. BMJ. 2016;353:i2089.

21. Guyatt G, Oxman AD, Akl EA, Kunz R, Vist G, Brozek J, et al. GRADE guidelines: 1. Introduction-GRADE evidence profiles and summary of findings tables. J Clin Epidemiol. 2011:64(4):383-94.

22. Guyatt GH, Oxman AD, Vist GE, Kunz R, Falck-Ytter Y, Alonso-Coello P, et al. GRADE: an emerging consensus on rating quality of evidence and strength of recommendations. BMJ. 2008;336(7650):924-6.

23. Boulware DR, Pullen MF, Bangdiwala AS, Pastick KA, Lofgren SM, Okafor EC, et al. A Randomized trial of hydroxychloroquine as postexposure prophylaxis for Covid-19. N Engl J Med. 2020;383(6):517-25.

24. Cavalcanti AB, Zampieri FG, Rosa RG, Azevedo LCP, Veiga VC, Avezum A, et al. Hydroxychloroquine with or without azithromycin in mild-tomoderate Covid-19. N Engl J Med. 2020.

25. Chen J, Liu D, Liu L, Liu P, Xu Q, Xia L, et al. A pilot study of hydroxychloroquine in treatment of patients with moderate COVID-19. Zhejiang Da Xue Xue Bao Yi Xue Ban. 2020;49(2):215-9.

26. Chen Z, Hu J, Zhang Z, Jiang S, Han S, Yan D, et al. Efficacy of hydroxychloroquine in patients with COVID-19: results of a randomized clinical trial. medRxiv. 2020:2020.03.22.20040758.

27. Mitja O, Corbacho-Monne M, Ubals M, Tebe C, Penafiel J, Tobias A, et al. Hydroxychloroquine for Early treatment of adults with mild Covid-19: a randomized-controlled trial. Clin Infect Dis. 2020.

28. Skipper CP, Pastick KA, Engen NW, Bangdiwala AS, Abassi M, Lofgren SM et al. Hydroxychloroquine in nonhospitalized adults with early COVID19: a randomized trial. Ann Intern Med. 2020.

29. Tang W, Cao Z, Han M, Wang Z, Chen J, Sun W, et al. Hydroxychloroquine in patients with mainly mild to moderate coronavirus disease 2019: open label, randomised controlled trial. BMJ. 2020:369:m1849.

30. RECOVERY, Horby P, Mafham M, Linsell L, Bell JL, Staplin N, et al. Effect of Hydroxychloroquine in hospitalized patients with COVID-19: preliminary results from a multi-centre, randomized, controlled trial. medRxiv. 2020:2020.07.15.20151852.

31. Abella BS, Jolkovsky EL, Biney BT, Uspal JE, Hyman MC, Frank I, et al. Efficacy and safety of hydroxychloroquine vs placebo for pre-exposure SARS-CoV-2 prophylaxis among health care workers: a randomized clinical trial. JAMA Intern Med. 2021;181(2):195-202.

32. Barnabas RV, Brown ER, Bershteyn A, Stankiewicz Karita HC, Johnston $C$, Thorpe LE, et al. Hydroxychloroquine as postexposure prophylaxis to prevent severe acute respiratory syndrome coronavirus 2 infection : a randomized trial. Ann Intern Med. 2021;174(3):344-52.

33. Chen CP, Lin YC, Chen TC, Tseng TY, Wong HL, Kuo CY, et al. A multicenter, randomized, open-label, controlled trial to evaluate the efficacy and tolerability of hydroxychloroquine and a retrospective study in adult patients with mild to moderate coronavirus disease 2019 (COVID19). PLoS One. 2020;15(12):e0242763.

34. Dubée V, Roy PM, Vielle B, Parot-Schinkel E, Blanchet O, Darsonval A, et al. Hydroxychloroquine in mild-to-moderate COVID-19: a placebocontrolled double blind trial. Clin Microbiol Infect. 2021. 
35. Johnston C, Brown ER, Stewart J, Karita HCS, Kissinger PJ, Dwyer J, et al. Hydroxychloroquine with or without azithromycin for treatment of early SARS-CoV-2 infection among high-risk outpatient adults: a randomized clinical trial. EClinicalMedicine. 2021;33:100773.

36. Lyngbakken MN, Berdal JE, Eskesen A, Kvale D, Olsen IC, Rueegg CS, et al. A pragmatic randomized controlled trial reports lack of efficacy of hydroxychloroquine on coronavirus disease 2019 viral kinetics. Nat Commun. 2020;11(1):5284.

37. Mitjà $\mathrm{O}$, Corbacho-Monné $\mathrm{M}$, Ubals $\mathrm{M}$, Alemany $\mathrm{A}$, Suñer $\mathrm{C}$, Tebé $\mathrm{C}$, et al. A cluster-randomized trial of hydroxychloroquine for prevention of Covid-19. N Engl J Med. 2021;384(5):417-27.

38. Omrani AS, Pathan SA, Thomas SA, Harris TRE, Coyle PV, Thomas $C E$, et al. Randomized double-blinded placebo-controlled trial of hydroxychloroquine with or without azithromycin for virologic cure of non-severe Covid-19. EClinicalMedicine. 2020;29:100645.

39. Rajasingham R, Bangdiwala AS, Nicol MR, Skipper CP, Pastick KA, Axelrod $M L$, et al. Hydroxychloroquine as pre-exposure prophylaxis for COVID19 in healthcare workers: a randomized trial. Clin Infect Dis. 2020.

40. Reis G, Moreira Silva E, Medeiros Silva DC, Thabane L, Singh G, Park JJH, et al. Effect of early treatment with hydroxychloroquine or lopinavir and ritonavir on risk of hospitalization among patients with COVID19: The TOGETHER Randomized Clinical Trial. JAMA Netw Open. 2021;4(4):e216468.

41. Self WH, Semler MW, Leither LM, Casey JD, Angus DC, Brower RG, et al. Effect of Hydroxychloroquine on clinical status at 14 days in hospitalized patients with COVID-19: a randomized clinical trial. JAMA. 2020;324(21):2165-76.

42. Ulrich RJ, Troxel AB, Carmody E, Eapen J, Bäcker M, DeHovitz JA, et al. Treating COVID-19 with hydroxychloroquine (TEACH): a multicenter, double-blind randomized controlled trial in hospitalized patients. Open Forum Infect Dis. 2020;7(10):ofaa446.

43. Cox SE, Nweneka CV, Doherty CP, Fulford AJ, Moore SE, Prentice AM. Randomised controlled trial of weekly chloroquine to re-establish normal erythron iron flux and haemoglobin recovery in postmalarial anaemia. BMJ Open. 2013;3(7).

44. Dunyo S, Ord R, Hallett R, Jawara M, Walraven G, Mesa E, et al. Randomised trial of chloroquine/sulphadoxine-pyrimethamine in Gambian children with malaria: impact against multidrug-resistant P. falciparum. PLoS Clin Trials. 2006;1 (3):e14.

45. Endy TP, Keiser PB, Cibula D, Abbott M, Ware L, Thomas SJ, et al. Effect of antimalarial drugs on the immune response to intramuscular rabies vaccination using a postexposure prophylaxis regimen. J Infect Dis. 2020;221(6):927-33.

46. Fernando D, De Silva D, Carter R, Mendis KN, Wickremasinghe R. A randomized, double-blind, placebo-controlled, clinical trial of the impact of malaria prevention on the educational attainment of school children. Am J Trop Med Hyg. 2006;74(3):386-93.

47. Fryauff DJ, Baird JK, Basri H, Sumawinata I, Purnomo, Richie TL, et al. Randomised placebo-controlled trial of primaquine for prophylaxis of falciparum and vivax malaria. Lancet. 1995;346(8984):1190-3.

48. Galatas B, Nhamussua L, Candrinho B, Mabote L, Cisteró P, Gupta H, et al. In-vivo efficacy of chloroquine to clear asymptomatic infections in mozambican adults: a randomized, placebo-controlled trial with implications for elimination strategies. Sci Rep. 2017;7(1):1356.

49. Gasasira AF, Dorsey G, Nzarubara B, Staedke SG, Nassali A, Rosenthal PJ, et al. Comparative efficacy of aminoquinoline-antifolate combinations for the treatment of uncomplicated falciparum malaria in Kampala, Uganda. Am J Trop Med Hyg. 2003;68(2):127-32.

50. Michel R, Bardot S, Queyriaux B, Boutin JP, Touze JE. Doxycycline-chloroquine vs. doxycycline-placebo for malaria prophylaxis in nonimmune soldiers: a double-blind randomized field trial in sub-Saharan Africa. Trans R Soc Trop Med Hyg. 2010;104(4):290-7.

51. Miller AK, Harrell E, Ye L, Baptiste-Brown S, Kleim JP, Ohrt C, et al. Pharmacokinetic interactions and safety evaluations of coadministered tafenoquine and chloroquine in healthy subjects. Br J Clin Pharmacol. 2013;76(6):858-67.

52. Ndyomugyenyi R, Magnussen $P$, Clarke $S$. The efficacy of chloroquine, sulfadoxine-pyrimethamine and a combination of both for the treatment of uncomplicated Plasmodium falciparum malaria in an area of low transmission in western Uganda. Tropical Med Int Health. 2004;9(1):47-52.
53. Salako LA, Adio RA, Walker O, Sowunmi A, Stürchler D, Mittelholzer ML, et al. Mefloquine-sulphadoxine-pyrimethamine (Fansimef, Roche) in the prophylaxis of Plasmodium falciparum malaria: a double-blind, comparative, placebo-controlled study. Ann Trop Med Parasitol. 1992;86(6):575-81.

54. Vicente J, Zusterzeel R, Johannesen L, Ochoa-Jimenez R, Mason JW, Sanabria C, et al. Assessment of multi-ion channel block in a phase I randomized study design: results of the CiPA phase I ECG biomarker validation study. Clin Pharmacol Ther. 2019;105(4):943-53.

55. Villegas L, McGready R, Htway M, Paw MK, Pimanpanarak M, Arunjerdja $R$, et al. Chloroquine prophylaxis against vivax malaria in pregnancy: a randomized, double-blind, placebo-controlled trial. Trop Med Int Health. 2007;12(2):209-18.

56. Engchanil C, Kosalaraksa P, Lumbiganon P, Lulitanond V, Pongjunyakul $P$, Thuennadee $R$, et al. Therapeutic potential of chloroquine added to zidovudine plus didanosine for HIV-1 infected children. J Med Assoc Thail. 2006;89(8):1229-36.

57. Jacobson JM, Bosinger SE, Kang M, Belaunzaran-Zamudio P, Matining RM, Wilson CC, et al. The effect of chloroquine on immune activation and interferon signatures associated with HIV-1. AIDS Res Hum Retrovir. 2016;32(7):636-47.

58. Kamgno J, Djomo PN, Pion SD, Thylefors B, Boussinesq M. A controlled trial to assess the effect of quinine, chloroquine, amodiaquine, and artesunate on loa loa microfilaremia. Am J Trop Med Hyg. 2010;82(3):379-85.

59. De Lamballerie X, Boisson V, Reynier JC, Enault S, Charrel RN, Flahault $A$, et al. On chikungunya acute infection and chloroquine treatment. Vector Borne Zoonotic Dis. 2008;8(6):837-9.

60. Majzoobi MM, Hashemi SH, Mamani M, Keramat F, Poorolajal J, Ghasemi Basir HR. Effect of hydroxychloroquine on treatment and recurrence of acute brucellosis: a single-blind, randomized clinical trial. Int J Antimicrob Agents. 2018;51(3):365-9.

61. Peymani P, Yeganeh B, Sabour S, Geramizadeh B, Fattahi MR, Keyvani $H$, et al. New use of an old drug: Chloroquine reduces viral and ALT levels in HCV non-responders (a randomized, triple-blind, placebocontrolled pilot trial). Can J Physiol Pharmacol. 2016;94(6):613-9.

62. Pappaioanou M, Fishbein DB, Dreesen DW, Schwartz IK, Campbell $\mathrm{GH}$, Sumner JW, et al. Antibody response to preexposure human diploid-cell rabies vaccine given concurrently with chloroquine. $N$ Engl J Med. 1986;314(5):280-4.

63. Paton NI, Lee L, Xu Y, Ooi EE, Cheung YB, Archuleta S, et al. Chloroquine for influenza prevention: a randomised, double-blind, placebo controlled trial. Lancet Infect Dis. 2011;11(9):677-83.

64. Paton NI, Goodall RL, Dunn DT, Franzen S, Collaco-Moraes Y, Gazzard BG, et al. Effects of hydroxychloroquine on immune activation and disease progression among HIV-infected patients not receiving antiretroviral therapy: a randomized controlled trial. JAMA. 2012;308(4):353-61.

65. Terrabuio D, Diniz M, Falcao L, Guedes A, Nakano L, Evangelista $A$, et al. Chloroquine Is effective for maintenance of remission in autoimmune hepatitis: controlled, double-blind, randomized trial. Hepatol Commun. 2018;3(1):116-28.

66. Tricou V, Minh NN, Van TP, Lee SJ, Farrar J, Wills B, et al. A randomized controlled trial of chloroquine for the treatment of dengue in Vietnamese adults. PLoS Negl Trop Dis. 2010;4(8):e785.

67. Sperber K, Louie M, Kraus T, Proner J, Sapira E, Lin S, et al. Hydroxychloroquine treatment of patients with human immunodeficiency virus type 1. Clin Ther. 1995;17(4):622-36.

68. Blackburn WD Jr, Malin Prupas H, Silverfield JC, Poiley JE, Caldwell JR, Collins RL, et al. Tenidap in rheumatoid arthritis: A 24-week doubleblind comparison with hydroxychloroquine-plus-piroxicam, and piroxicam alone. Arthritis Rheum. 1995;38(10):1447-56.

69. Bonfante HL, Machado LG, Capp AA, Paes MAdS, Levy RA, Teixeira HC. Assessment of the use of hydroxychloroquine on knees' osteoarthritis treatment. Rev Bras Reumatol. 2008;48(4):208-12.

70. Brewer EJ, Giannini EH, Kuzmina N, Alekseev L. Penicillamine and hydroxychloroquine in the treatment of severe juvenile rheumatoid arthritis. Results of the U.S.A.-U.S.S.R. double-blind placebo-controlled trial. N Engl J Med. 1986;314(20):1269-76.

71. Bunch TW, O'Duffy JD, Tompkins RB, O'Fallon WM. Controlled trial of hydroxychloroquine and D-penicillamine singly and in 
combination in the treatment of rheumatoid arthritis. Arthritis Rheum. 1984;27(3):267-76.

72. Clark P, Casas E, Tugwell P, Medina C, Gheno C, Tenorio G, et al. Hydroxychloroquine compared with placebo in rheumatoid arthritis: a randomized controlled trial. Ann Intern Med. 1993;119(11):1067-71.

73. Davis MJ, Dawes PT, Fowler PD, Clarke S, Fisher J, Shadforth MF. Should disease-modifying agents be used in mild rheumatoid arthritis? Br J Rheumatol. 1991;30(6):451-4.

74. Das SK, Pareek A, Mathur DS, Wanchu A, Srivastava R, Agarwal GG, et al. Efficacy and safety of hydroxychloroquine sulphate in rheumatoid arthritis: a randomized, double-blind, placebo controlled clinical trial - an Indian experience. Curr Med Res Opin. 2007;23(9):2227-34.

75. Esdaile JM, Suissa S, Shiroky JB, Lamping D, Tsakonas E, Anderson D, et al. A randomized trial of hydroxychloroquine in early rheumatoid arthritis: the HERA study. Am J Med. 1995;98(2):156-68.

76. Erkan D, Unlu O, Sciascia S, Belmont HM, Branch DW, Cuadrado MJ, et al. Hydroxychloroquine in the primary thrombosis prophylaxis of antiphospholipid antibody positive patients without systemic autoimmune disease. Lupus. 2018;27(3):399-406.

77. Faarvang KL, Egsmose C, Kryger P, Podenphant J, Ingeman-Nielsen M, Hansen TM. Hydroxychloroquine and sulphasalazine alone and in combination in rheumatoid arthritis: a randomised double blind trial. Ann Rheum Dis. 1993;52(10):711-5.

78. Ferraz MB, Pinheiro GRC, Heffenstein M, Albuquerque E, Rezende $C$, Roimicher $\mathrm{L}$, et al. Combination therapy with methotrexate and chloroquine in rheumatoid arthritis. Scand J Rheumatol. 1994;23(5):231-6.

79. Freedman A, Steinberg VL. Chloroquine in rheumatoid arthritis; a double blindfold trial of treatment for one year. Ann Rheum Dis. 1960;19(3):243-50.

80. Gibson T, Emery P, Armstrong RD, Crisp AJ, Panayi GS. Combined D-penicillamine and chloroquine treatment of rheumatoid arthritis--a comparative study. Br J Rheumatol. 1987;26(4):279-84.

81. Gottenberg JE, Ravaud P, Puéchal X, Le Guern V, Sibilia J, Goeb V, et al. Effects of hydroxychloroquine on symptomatic improvement in primary sjögren syndrome: The JOQUER randomized clinical trial. JAMA. 2014;312(3):249-58.

82. Haar D, Solvkjaer M, Unger B, Rasmussen KJE, Christensen L, Hansen TM. A double-blind comparative study of hydroxychloroquine and dapsone, alone and in combination, in rheumatoid arthritis. Scand J Rheumatol. 1993;22(3):113-8.

83. Jokar M, Mirfeizi Z, Keyvanpajouh K. The effect of hydroxychloroquine on symptoms of knee osteoarthritis: A double-blind randomized controlled clinical trial. Iran J Med Sci. 2013;38(3):221-6.

84. Kavanaugh A, Adams-Huet B, Jain R, Denke M, McFarlin J. Hydroxychloroquine effects on lipoprotein profiles (the HELP trial): a double-blind, randomized, placebo-controlled, pilot study in patients with systemic lupus erythematosus. J Clin Rheumatol. 1997;3(1):3-8.

85. Kingsbury SR, Tharmanathan P, Keding A, Ronaldson SJ, Grainger A, Wakefield RJ, et al. Hydroxychloroquine effectiveness in reducing symptoms of hand osteoarthritis a randomized trial. Ann Intern Med. 2018;168(6):385-95

86. Kraak JH, Van Ketel W, Prakken JR, Van Zwet W. The value of hydroxychloroquine (plaquenil) for the treatment of chronic discoid lupus erythematosus; a double blind trial. Dermatologica. 1965;130:293-305.

87. Kravvariti E, Koutsogianni A, Samoli E, Sfikakis PP, Tektonidou MG. The effect of hydroxychloroquine on thrombosis prevention and antiphospholipid antibody levels in primary antiphospholipid syndrome: a pilot open label randomized prospective study. Autoimmun Rev. 2020;19(4):102491.

88. Kruize AA, Hene RJ, Kallenberg CGM, Van Bijsterveld OP, Van Der Heide $A$, Kater $L$, et al. Hydroxychloroquine treatment for primary Sjogren's syndrome: a two year double blind crossover trial. Ann Rheum Dis. 1993;52(5):360-4.

89. Lee W, Ruijgrok L, Boxma-de Klerk B, Kok MR, Kloppenburg M, Gerards $A$, et al. Efficacy of hydroxychloroquine in hand osteoarthritis: a randomized, double-blind, placebo-controlled trial. Arthritis Care Res. 2018;70(9):1320-5.

90. Levy RA, Vilela VS, Cataldo MJ, Ramos RC, Duarte JLMB, Tura BR, et al. Hydroxychloroquine (HCQ) in lupus pregnancy: double-blind and placebo-controlled study. Lupus. 2001;10(6):401-4.
91. Meinão IM, Sato El, Andrade LE, Ferraz MB, Atra E. Controlled trial with chloroquine diphosphate in systemic lupus erythematosus. Lupus. 1996;5(3):237-41.

92. Miranda JM, Alvarez-Nemegyei J, Saavedra MA, Terán L, Galván-Villegas F, García-Figueroa J, et al. A randomized, double-blind, multicenter, controlled clinical trial of cyclosporine plus chloroquine vs. cyclosporine plus placebo in early-onset rheumatoid arthritis. Arch Med Res. 2004;35(1):36-42.

93. O'Dell JR, Leff R, Paulsen G, Haire C, Mallek J, Eckhoff PJ, et al. Treatment of rheumatoid arthritis with methotrexate and hydroxychloroquine, methotrexate and sulfasalazine, or a combination of the three medications: results of a two-year, randomized, double-blind, placebo-controlled trial. Arthritis Rheum. 2002;46(5):1164-70.

94. Sarzi-Puttini P, D'Ingianna E, Fumagalli M, Scarpellini M, Fiorini T, Chérié-Lignière EL, et al. An open, randomized comparison study of cyclosporine A, cyclosporine A + methotrexate and cyclosporine A + hydroxychloroquine in the treatment of early severe rheumatoid arthritis. Rheumatol Int. 2005;25(1):15-22.

95. Scott DL, Dawes PT, Tunn E, Fowler PD, Shadforth MF, Fisher J, et al. Combination therapy with gold and hydroxychloroquine in rheumatoid arthritis: a prospective, randomized placebo-controlled study. $\mathrm{Br} J$ Rheumatol. 1989;28(2):128-33.

96. Van Jaarsveld CHM, Jahangier ZN, Jacobs JWG, Blaauw AAM, Van Albada-Kuipers GA, Ter Borg EJ, et al. Toxicity of anti-rheumatic drugs in a randomized clinical trial of early rheumatoid arthritis. Rheumatology. 2000;39(12):1374-82.

97. Yokogawa N, Eto H, Tanikawa A, Ikeda T, Yamamoto K, Takahashi T, et al. Effects of hydroxychloroquine in patients with cutaneous lupus erythematosus: a multicenter, double-blind, randomized, parallel-group trial. Arthritis Rheum. 2017;69(4):791-9.

98. Yoon CH, Lee HJ, Lee EY, Lee EB, Lee WW, Kim MK, et al. Effect of hydroxychloroquine treatment on dry eyes in subjects with primary Sjögren's syndrome: a double-blind randomized control study. J Korean Med Sci. 2016;31(7):1127-35

99. Boonpiyathad T, Sangasapaviliya A. Hydroxychloroquine in the treatment of anti-histamine refractory chronic spontaneous urticaria, randomized single-blinded placebo-controlled trial and an open label comparison study. Eur Ann Allergy Clin Immunol. 2017;49(5):220-4.

100. Jacobs PH, Tromovitch TA. Lucasg, Puzak HP. Effect of chlorquine and placebo on warts. Arch Dermatol. 1963;87:89-90.

101. Murphy GM, Hawk JLM, Magnus IA. Hydroxychloroquine in polymorphic light eruption: A controlled trial with drug and visual sensitivity monitoring. Br J Dermatol. 1987;116(3):379-86.

102. Reeves GEM, Boyle MJ, Bonfield J, Dobson P, Loewenthal M. Impact of hydroxychloroquine therapy on chronic urticaria: chronic autoimmune urticaria study and evaluation. Intern Med J. 2004;34(4):182-6.

103. Arnaout A, Robertson SJ, Pond GR, Lee H, Jeong A, lanni L, et al. A randomized, double-blind, window of opportunity trial evaluating the effects of chloroquine in breast cancer patients. Breast Cancer Res Treat. 2019;178(2):327-35.

104. Brazil L, Swampillai AL, Mak KM, Edwards D, Mesiri P, Clifton-Hadley L, et al. Hydroxychloroquine and short-course radiotherapy in elderly patients with newly diagnosed high-grade glioma: a randomized phase II trial. Neurooncol Adv. 2020;2(1):vdaa046.

105. Briceño E, Reyes S, Sotelo J. Therapy of glioblastoma multiforme improved by the antimutagenic chloroquine. Neurosurg Focus. 2003;14(2):e3.

106. Gilman AL, Schultz KR, Goldman FD, Sale GE, Krailo MD, Chen Z, et al. Randomized trial of hydroxychloroquine for newly diagnosed chronic graft-versus-host disease in children: a Children's Oncology Group study. Biol Blood Marrow Transplant. 2012;18(1):84-91.

107. Karasic TB, O'Hara MH, Loaiza-Bonilla A, Reiss KA, Teitelbaum UR, Borazanci E, et al. Effect of gemcitabine and nab-paclitaxel with or without hydroxychloroquine on patients with advanced pancreatic cancer: a phase 2 randomized clinical trial. JAMA Oncol. 2019;5(7):993-8.

108. Rojas-Puentes LL, Gonzalez-Pinedo M, Crismatt A, Ortega-Gomez A, Gamboa-Vignolle C, Nuñez-Gomez R, et al. Phase II randomized, double-blind, placebo-controlled study of whole-brain irradiation with concomitant chloroquine for brain metastases. Radiat Oncol. 2013;8(1).

109. Sotelo J, Briceño E, López-González MA. Adding chloroquine to conventional treatment for glioblastoma multiforme: a 
randomized, double-blind, placebo-controlled trial. Ann Intern Med. 2006;144(5):337-43.

110. Zeh H, Bahary N, Boone BA, Singhi AD, Miller-Ocuin JL, Normolle DP, et al. A randomized phase II preoperative study of autophagy inhibition with high-dose hydroxychloroquine and gemcitabine/nab-paclitaxel in pancreatic cancer patients. Clin Cancer Res. 2020:clincanres.4042.2019.

111. Gerstein HC, Thorpe KE, Wayne Taylor D, Brian Haynes R. The effectiveness of hydroxychloroquine in patients with type 2 diabetes mellitus who are refractory to sulfonylureas-a randomized trial. Diabetes Res Clin Pract. 2002;55(3):209-19.

112. McGill JB, Johnson M, Hurst S, Cade WT, Yarasheski KE, Ostlund RE, et al. Low dose chloroquine decreases insulin resistance in human metabolic syndrome but does not reduce carotid intima-media thickness. Diabetol Metab Syndr. 2019;11:61.

113. Pareek A, Chandurkar N, Thulaseedharan NK, Legha R, Agarwal M, Mathur SL, et al. Efficacy and safety of fixed dose combination of atorvastatin and hydroxychloroquine: a randomized, double-blind comparison with atorvastatin alone among Indian patients with dyslipidemia. Curr Med Res Opin. 2015;31(11):2105-17.

114. Quatraro A, Consoli G, Magno M, Caretta F, Nardozza A, Ceriello A, et al. Hydroxychloroquine in decompensated, treatment-refractory noninsulin-dependent diabetes mellitus. A new job for an old drug? Ann Intern Med. 1990;112(9):678-81.

115. Wasko MCM, McClure CK, Kelsey SF, Huber K, Orchard T, Toledo FGS. Antidiabetogenic effects of hydroxychloroquine on insulin sensitivity and beta cell function: a randomised trial. Diabetologia. 2015;58(10):2336-43.

116. Chakravarti HN, Nag A. Efficacy and safety of hydroxychloroquine as add-on therapy in uncontrolled type 2 diabetes patients who were using two oral antidiabetic drugs. J Endocrinol Investig. 2021:44(3):481-92.

117. Toledo FGS, Miller RG, Helbling NL, Zhang Y, DeLany JP. The effects of hydroxychloroquine on insulin sensitivity, insulin clearance and inflammation in insulin-resistant adults: a randomized trial. Diabetes Obes Metab. 2021.

118. Fong T, Trinkaus K, Adkins D, Vij R, Devine SM, Tomasson M, et al. A randomized double-blind trial of hydroxychloroquine for the prevention of chronic graft-versus-host disease after allogeneic peripheral blood stem cell transplantation. Biol Blood Marrow Transplant. 2007;13(10):1201-6.

119. Horne GA, Stobo J, Kelly C, Mukhopadhyay A, Latif AL, Dixon-Hughes $J$, et al. A randomised phase II trial of hydroxychloroquine and imatinib versus imatinib alone for patients with chronic myeloid leukaemia in major cytogenetic response with residual disease. Leukemia. 2020;34(7):1775-86.

120. Liu LJ, Yang YZ, Shi SF, Bao YF, Yang C, Zhu SN, et al. Effects of hydroxychloroquine on proteinuria in IgA nephropathy: a randomized controlled trial. Am J Kidney Dis. 2019;74(1):15-22.

121. Charous BL, Halpern EF, Steven GC. Hydroxychloroquine improves airflow and lowers circulating IgE levels in subjects with moderate symptomatic asthma. J Allergy Clin Immunol. 1998;102(2):198-203.

122. Roberts JA, Gunneberg A, Elliott JA, Thomson NC. Hydroxychloroquine in steroid dependent asthma. Pulm Pharmacol. 1988;1 (1):59-61.
123. Van Gool WA, Weinstein HC, Scheltens P, Walstra GJ. Effect of hydroxychloroquine on progression of dementia in early Alzheimer's disease: an 18-month randomised, double-blind, placebo-controlled study. Lancet. 2001;358(9280):455-60.

124. Desta M, Tadesse A, Gebre N, Barci BM, Torrey EF, Knable MB. Controlled trial of hydroxychloroquine in schizophrenia. J Clin Psychopharmacol. 2002;22(5):507-10.

125. Achuthan S, Ahluwalia J, Shafiq N, Bhalla A, Pareek A, Chandurkar N, et al. Hydroxychloroquine's efficacy as an antiplatelet agent study in healthy volunteers: a proof of concept study. J Cardiovasc Pharmacol Ther. 2015;20(2):174-80.

126. Snook GA, Chrisman OD, Wilson TC. Thromboembolism after surgical treatment of hip fractures. Clin Orthop Relat Res. 1981;155:21-4.

127. Parrow A, Samuelsson SM. Use of chloroquine phosphate--a new treatment for spontaneous leg cramps. Acta Med Scand. 1967;181(2):237-44.

128. Soltani A, Moayyeri A, Azizi F. Combination therapy of chloroquine and methimazole in Graves' disease: A pilot randomized controlled trial. Biomed Pharmacother. 2007;61(4):241-3.

129. Ponticelli C, Moroni G. Hydroxychloroquine in systemic lupus erythematosus (SLE). Expert Opin Drug Saf. 2017;16(3):411-9.

130. Costedoat-Chalumeau N, Amoura Z, Huong DL, Lechat P, Piette JC. Safety of hydroxychloroquine in pregnant patients with connective tissue diseases. Review of the literature. Autoimmun Rev. 2005;4(2):111-5.

131. Wolfe MS, Cordero JF. Safety of chloroquine in chemosuppression of malaria during pregnancy. Br Med J. 1985;290(6480):1466-7.

132. Pereira D, Daher A, Zanini G, Maia I, Fonseca L, Pitta L, et al. Safety, efficacy and pharmacokinetic evaluations of a new coated chloroquine tablet in a single-arm open-label non-comparative trial in Brazil: a step towards a user-friendly malaria vivax treatment. Malar J. 2016;15:477.

133. Shafi AMA, Shaikh SA, Shirke MM, Iddawela S, Harky A. Cardiac manifestations in COVID-19 patients-A systematic review. J Card Surg. 2020;35(8):1988-2008.

134. Ren L, Xu W, Overton JL, Yu S, Chiamvimonvat N, Thai PN. Assessment of hydroxychloroquine and chloroquine safety profiles: a systematic review and meta-analysis. medRxiv. 2020.

135. Eljaaly K, Alireza KH, Alshehri S, Al-Tawfiq JA. Hydroxychloroquine safety: a meta-analysis of randomized controlled trials. Travel Med Infect Dis. 2020;101812.

136. Golder S, Loke YK, Wright K, Norman G. Reporting of adverse events in published and unpublished studies of health care interventions: a systematic review. PLoS Med. 2016;13(9):e1002127.

137. Bradburn MJ, Deeks JJ, Berlin JA, Russell Localio A. Much ado about nothing: a comparison of the performance of meta-analytical methods with rare events. Stat Med. 2007;26(1):53-77.

\section{Publisher's Note}

Springer Nature remains neutral with regard to jurisdictional claims in published maps and institutional affiliations.

Ready to submit your research? Choose BMC and benefit from

- fast, convenient online submission

- thorough peer review by experienced researchers in your field

- rapid publication on acceptance

- support for research data, including large and complex data types

- gold Open Access which fosters wider collaboration and increased citations

- maximum visibility for your research: over $100 \mathrm{M}$ website views per year

At BMC, research is always in progress.

Learn more biomedcentral.com/submissions 